Illinois State University

ISU ReD: Research and eData

Theses and Dissertations

$4-4-2018$

\title{
The Effects of Instructors Discussing Alcohol In The Classroom on Student Perceptions of Their Instructor
}

Nathaniel Swiech Brophy

Illinois State University, nbrophy@gmu.edu

Follow this and additional works at: https://ir.library.illinoisstate.edu/etd

Part of the Communication Commons

\section{Recommended Citation}

Brophy, Nathaniel Swiech, "The Effects of Instructors Discussing Alcohol In The Classroom on Student Perceptions of Their Instructor" (2018). Theses and Dissertations. 845.

https://ir.library.illinoisstate.edu/etd/845

This Thesis is brought to you for free and open access by ISU ReD: Research and eData. It has been accepted for inclusion in Theses and Dissertations by an authorized administrator of ISU ReD: Research and eData. For more information, please contact ISUReD@ilstu.edu. 


\title{
THE EFFECTS OF INSTRUCTORS DISCUSSING ALCOHOL IN THE CLASSROOM ON STUDENT PERCEPTIONS OF THEIR INSTRUCTOR
}

\author{
Nathaniel Swiech Brophy
}

86 Pages

This thesis is comprised of two studies. Study One is a qualitative exploratory analysis which attempts to uncover students' experiences with instructors discussing alcohol in the university classroom and how the appropriateness of this behavior is determined. How this mention of alcohol affects the students' perception of the instructor, as well as the relationship between perceived appropriateness of the behavior and change in perception, are also investigated. Study One found that students have experienced their instructors mentioning alcohol in the classroom as normative student behavior, as part of the formal curriculum, and as personal self-disclosing about alcohol use. Participants determined the appropriateness of mentioning alcohol based on its perceived relevance to students or class. Study Two sought to determine how instructor discussion of alcohol in the classroom affects the way students perceive them. Specifically, it examines how instructor's advocating for safe drinking behavior, mentioning their personal alcohol use behaviors, introducing alcohol as part of the curriculum, or discussing student future and past alcohol use affect rapport, homophily, and credibility. The data indicated that instructors advocating for student safe drinking had the most positive impact on all three measures, whereas instructors who discussed their personal drinking behaviors in the classroom had significantly lower scores on rapport, homophily, and credibility.

KEYWORDS: instructor; alcohol; classroom; perception; rapport; homophily; credibility 


\title{
THE EFFECTS OF INSTRUCTORS DISCUSSING ALCOHOL IN THE CLASSROOM ON STUDENT PERCEPTIONS OF THEIR INSTRUCTOR
}

\author{
NATHANIEL SWIECH BROPHY
}

\author{
A Thesis Submitted in Partial \\ Fulfillment of the Requirements \\ for the Degree of \\ MASTER OF SCIENCE \\ School of Communication \\ ILLINOIS STATE UNIVERSITY
}


(C) 2018 Nathaniel Swiech Brophy 


\title{
THE EFFECTS OF INSTRUCTORS DISCUSSING ALCOHOL IN THE CLASSROOM ON STUDENT PERCEPTIONS OF THEIR INSTRUCTOR
}

\author{
NATHANIEL SWIECH BROPHY
}

COMMITTEE MEMBERS:

John F. Hooker, Chair

John R. Baldwin

Kevin R. Meyer

Stephen K. Hunt 


\section{ACKNOWLEDGMENTS}

I would first like to thank my late Great Aunt Joyce. She was the secret benefactor who funded my undergraduate degree, and her gift of higher education has meant a great deal to me. My Aunt Joyce is the primary reason I was able to attend Illinois State University; for her amazing act of altruism, I dedicate this thesis to her.

I would like to thank Dr. Hooker, my chair, for his numerous hours of mentorship and for responding to my endless and increasingly specific quantitative questions. Thank you, Dr. Baldwin, Dr. Hunt, and Dr. Meyer for your incredibly helpful feedback; the three of you have helped me become a better researcher and writer. Thank you to Dr. Cochece Davis for encouraging me to become a better scholar and to attend graduate school; I would not have considered a graduate degree without your guidance.

The friends who supported me academically and emotionally during my time at ISU also deserve a special thanks. Thank you, Corey Green, for being such an understanding, selfsacrificing, and caring confidant; I would not have made it through graduate school without your support - and occasional gourmet meals. Thank you, Cecelia Long and Joe Rice, for helping me remember that life is about more than just work, and it is important to leave the house and have fun every once in a while. Thank you to the fantastic Megan Ponti for loaning me her laptop.

Finally, thank you, Dawn Swiech and Nick Brophy, my parents, for the emotional and financial support you provided during my time at Illinois State. When I struggled as an undergraduate, you two pushed me to return to academia and it was one of the best decisions I have ever made. Also, thank you, Karly, for dog-sitting my beloved Drogo when I had to spend hours in Fell and was unable to leave work to spend time with him; we both appreciate it.

N. S. B. 


\section{CONTENTS}

\section{Page}

ACKNOWLEDGMENTS

$\begin{array}{ll}\text { CONTENTS ii } & \text { ii }\end{array}$

TABLES Di v vi

FIGURES vii

CHAPTER I: INTRODUCTION 1

CHAPTER II: LITERATURE REVIEW

Alcohol Consumption and Perceptions in Higher Education 3

Curriculum Infusion $\quad 4$

Students and Alcohol Use Norms

$\begin{array}{ll}\text { Instructors and Alcohol Use Norms } & 6\end{array}$

CHAPTER III: STUDY ONE - QUALITATIVE STUDY 8

Qualitative Method $\quad 9$

$\begin{array}{ll}\text { Data Collection } & 9\end{array}$

$\begin{array}{ll}\text { Questionnaire } & 9\end{array}$

$\begin{array}{ll}\text { Sampling } & 9\end{array}$

$\begin{array}{ll}\text { Demographics } & 10\end{array}$

$\begin{array}{ll}\text { Data Analysis } & 10\end{array}$

$\begin{array}{ll}\text { Research question one } & 10\end{array}$

Research question two. $\quad 11$

$\begin{array}{lr}\text { Research question three. } & 12\end{array}$

$\begin{array}{ll}\text { Research question four. } & 12\end{array}$ 
Qualitative Research Results

How Instructors Discuss Alcohol in the Classroom

(1) Student alcohol use as normative.

(2) Alcohol in the curriculum.

(3) Instructor personal alcohol use behaviors.

Appropriateness of Instructor Discussion of Alcohol 19

$\begin{array}{ll}\text { (1) Perceived as appropriate. } & 20\end{array}$

(2) Inappropriate. 21

Change in Perception of Instructor following Discussion of Alcohol 22

Relationship between Appropriateness and Change in Perception of Instructor 22

$\begin{array}{ll}\text { Qualitative Discussion } & 25\end{array}$

Summary of Findings 25

$\begin{array}{ll}\text { Strengths and Limitations } & 28\end{array}$

$\begin{array}{ll}\text { Conclusion } & 29\end{array}$

CHAPTER IV: STUDY TWO - QUANTITATIVE STUDY 30

$\begin{array}{ll}\text { Literature Review } & 30\end{array}$

$\begin{array}{ll}\text { Instructor-Student Rapport } & 30\end{array}$

$\begin{array}{ll}\text { Instructor behavior. } & 31\end{array}$

$\begin{array}{ll}\text { Instructor humor. } & 32\end{array}$

$\begin{array}{ll}\text { Homophily } & 33\end{array}$

Instructor Credibility $\quad 35$

$\begin{array}{ll}\text { Caring. } & 35\end{array}$

$\begin{array}{ll}\text { Self-disclosure. } & 36\end{array}$ 
Quantitative Method

Participants

Sampling.

Demographics.

Research Design

Procedure

Results

Scale Reliability

Vignette Reliabilities

Descriptive and Injunctive Drinking Norms

Correlation between Dependent Variables

Multivariate Analysis

Quantitative Discussion

Descriptive and Injunctive Norms

Rapport

Homophily

Credibility

Strengths and Limitations

Conclusion

Summary of Findings

Qualitative Study (Study One)

Quantitative Study (Study Two) 
$\begin{array}{ll}\text { Future Research } & 59\end{array}$

$\begin{array}{ll}\text { Conclusion } & 60\end{array}$

$\begin{array}{lc}\text { REFERENCES } & 62\end{array}$

APPENDIX A: POSITIVE STUDENT OUTCOMES FROM INSTRUCTOR CREDIBILITY 75

APPENDIX B: CHARTS

$\begin{array}{ll}\text { APPENDIX C: SURVEY } & 78\end{array}$

APPENDIX D: VIGNETTES $\quad 84$ 


\section{TABLES}

Table

Page

1. Emergent Themes from Thematic and Axial Coding of Responses

2. Relationship between Relevance of Teacher Mention of Alcohol and Perceived Appropriateness

3. Change in Perception of Instructor

4. Relationship between Appropriateness and Change in Perception of Instructor

5. Manipulation Check with Tamhane's T2 Post-Hoc Test Results and Descriptive Statistics

6. Drinking Norms Descriptive Statistics

7. Sample Size, Means, Standard Deviations, and Pearson Correlations of DVs

8. MANOVA Post-Hoc Test Results and Descriptive Statistics

9. Positive Student Outcomes from Perceived Instructor Credibility 


\section{FIGURES}

Figure $\quad$ Page

1. Model of Research Question Four 13

2. Descriptive Drinking Norms Circle Graph 76

3. Injunctive Drinking Norms Question One Circle Graph 76

4. Injunctive Drinking Norms Question Two Circle Graph 77 


\section{CHAPTER I: INTRODUCTION}

Nearly $60 \%$ of college students surveyed in 2013 were current alcohol users (Substance Abuse and Mental Health Services Administration, 2014), and many students treat alcohol as an essential part of college life (Lederman \& Stewart, 2005). Few studies have explicitly researched the implications of instructors discussing alcohol in the classroom, despite past research demonstrating that students have experienced their instructors engaging in this behavior (Lederman \& Stewart, 2005; Nunziata, 2007; Wanzer, Frymier, Wojtaszczyk, \& Smith, 2006). Furthermore, researchers have found that instructors themselves acknowledge that they discuss alcohol in the classroom in varying degrees and contexts (North Dakota State University, 2014; Schlesselman, Nobre, \& English, 2011).

The idea for the present study was born out of my own experience as an undergraduate student at a midsized public Midwestern university. One day during the Fall 2014 semester, I was sitting in class and the instructor said something to the effect of, "Let's wrap today's lesson plan up soon, I have an unopened bottle of whiskey waiting for me at home." The instructor and several students chuckled, and she moved on with the lesson. This caught me off-guard and significantly violated my expectations for how I thought a college professor should behave in the classroom. That event was the first of many instances when I heard various instructors casually mention alcohol in the classroom. The way my instructors mentioned alcohol was not consistent, though. I noticed some alluding to the fact that their students might be hungover from bingedrinking the night before when they would say things like, "I know there was a special on pitchers of beer at the bars yesterday, but I need everyone to please wake up and pay attention this morning." 
After noting a few examples, I became curious about what impact this behavior might have on students. As an undergraduate student, I did some preliminary research to see what studies had been done on this topic and found, to my surprise, there was very little empirical research (Vangsness Frisch, 2016). Some studies have tangentially mentioned the subject (e.g., Wanzer et al., 2006), but, for the most part, instructors discussing alcohol in the classroom and its impact on students appeared to be understudied. The initial goals of the study were to examine how students had experienced the following: instructors' discussion of alcohol use in classroom situations (understood more broadly); the appropriateness of instructors' discussion of alcohol use in the classroom; whether the discussion of alcohol in the classroom caused a change in the students' perception of the instructor, and if it did, how so. Study One for the present thesis is an exploratory qualitative study that helped determine the independent and dependent variables for Study Two, the follow-up quantitative analysis. 


\section{CHAPTER II: LITERATURE REVIEW}

The association between alcohol use and college is as intertwined as the connection between education and college. According to Johnston, O'Malley, Bachman, Schulenberg, and Miech (2016), 81\% of college students surveyed in 2015 had tried alcohol, $68.6 \%$ reported having been drunk, and 32\% reported occasions of heavy drinking. While the researchers' findings actually show a steady decline in alcohol use since 2007 (Johnston et al., 2016), it is clear that alcohol is still part of the majority of American students' college experience. The ongoing relationship between alcohol and higher education is caused by a vicious cycle, where misperceptions about alcohol use reinforce the norm of alcohol abuse in college, and the norm then reinforces the misperceptions (Borsari \& Carey, 2001; Perkins, 2002a). Students enter college with the misperception of peer expectations of alcohol consumption, causing many to drink alcohol to fulfill "functions of bonding, sensation seeking, rite of passage, celebration, and seeking status" (Lui, Spaeth, \& Fread, 2013, p. 46). However, as discussed later, faculty can also play a role in the perpetuation of alcohol use in college as normative (Lederman \& Stewart, 2005; Perkins, 2002a).

\section{Alcohol Consumption and Perceptions in Higher Education}

While nearly $70 \%$ of students surveyed indicated that they had been drunk before (Johnston et al., 2016), research has shown that university students in the United States have exaggerated perceptions of how much their peers are actually drinking (Berkowitz, 2005;

Berkowitz, \& Perkins, 1986; Lederman \& Stewart, 2005; Lederman, Stewart, \& Russ, 2007; Perkins, 2002a; Perkins, Haines, \& Rice, 2005). In order to alter some of these misperceptions and reduce university students' drinking behaviors and the associated negative consequences, many institutions have begun implementing curriculum infusion programs. 


\section{Curriculum Infusion}

When alcohol is discussed in higher education classrooms, it is often brought up in the context of curriculum infusion. Curriculum infusion broadly refers to programs implemented on many college campuses that focus on changing university students' perceptions about alcohol (Lederman et al., 2007) as well as alcohol use behaviors (White, Park, \& Cordero, 2010). Specifically, curriculum infusion (CI) "is the act of interweaving prevention information concerning alcohol and other drugs into course content. CI involves the dissemination of substance use prevention content to students through existing academic courses" (Samuolis, Lazowski, \& Kessler, 2016, p. 737). Curriculum infusion has had mixed results. Lederman et al. found that CI was effective in reducing students' exaggerated misperceptions about their peers drinking. In a study attempting to reduce actual student consumption behaviors, White et al. found that there was no difference in alcohol consumption between those who received curriculum infusion in the classroom and those who did not; however, participants who were in the curriculum infusion treatment group reported significantly less negative consequences related to drinking compared to their peers in the control group. Most relevant to the present study, though, is that

Previous studies (Lederman \& Stewart, 2005; Perkins, 2002a, 2002b) have indicated that students often (mistakenly) perceive that faculty encourage dangerous drinking on campus by their references to drinking (e.g., "'I know it's hard to get up for a class on Friday mornings"'). A curriculum infusion approach positions faculty differently in relation to the subject. (Lederman et al., 2007, p. 490)

While the effectiveness of curriculum infusion is not within the purview of the present study, it is important to note that alcohol is being discussed in college classrooms as part of institutionally- 
backed programs (i.e., curriculum infusion) to address students' alcohol use misperceptions and drinking behaviors on campus.

\section{Students and Alcohol Use Norms}

Many students enter college with misperceptions about alcohol use, including the idea that alcohol misuse is normative behavior in higher education (Perkins, 2002a). According to Stewart et al. (2002),

These misperceptions lead students, faculty, parents, and alumni to believe that college is a place where everyone drinks a great deal. Heavy drinking as the perceived norm fosters the creation and maintenance of the cultural image of drinking as a rite of passage, as an inherent facet of college life. (p. 382)

University students have descriptive and injunctive drinking norms. Descriptive drinking norms are the perception of peer drinking quantity and frequency, while injunctive drinking norms are the moral rules of a peer group and the perceived approval of alcohol use (Borsari \& Carey, 2001). Research has shown that students overestimate both descriptive and injunctive drinking norms at their university, which leads to an overestimation of peer consumption of alcohol (Baer

\& Carney, 1993; Borsari \& Carey, 2001). Furthermore, Perkins and Wechsler (1996) found that a permissive acceptance of these norms is strongly correlated with greater personal alcohol abuse. The influence of peers on the misperception of alcohol abuse as normative is perhaps unsurprising (Borsari \& Carey, 2001), as Astin (1993) states that a "student's peer group is the single most potent source of influence on growth and development during the undergraduate years" (p. 398); however, the impact that instructors and faculty have on perpetuating this norm is less expected. 


\section{Instructors and Alcohol Use Norms}

Hansen (1997) suggests that faculty members should have a role in preventing, identifying, and treating student abuse of alcohol. However, researchers have found that, instead of preventing alcohol abuse, some instructors' discourse about student alcohol use in the classroom may actually perpetuate the behavior as normative (e.g., Lederman \& Stewart, 2005). In fact, Lui et al. (2013) posit that "the social norm of binge drinking is reinforced by "faculty members creating [a] dialogue about drinking within the classroom” (p. 41). Research has shown that students believe their instructors promulgate the idea of excessive alcohol consumption as the norm in college (Lederman \& Stewart, 2005). In their survey of 1,208 students at Rutgers University, Lederman and Stewart (2005) found that many students "felt that faculty reinforced the assumption that college students drink excessively by joking about alcohol in class (58\%) and by referring to Thursday night parties (43\%)" (p. 24). Similarly, research has shown that faculty recognize that they discuss their students' alcohol use in the classroom. Schlesselman et al.'s (2011) study found that $35 \%$ of 756 instructors surveyed acknowledged that they mentioned recreational alcohol use in the classroom one to three times in a semester. Another study found that $40 \%$ of 1,076 faculty members surveyed at North Dakota State University (2014) acknowledged that they discussed alcohol in front of students.

Instructors discussing alcohol use in the classroom is important since casual conversation about alcohol abuse can potentially perpetuate it as a college norm (Hansen, 1997; Lederman \& Stewart, 2005; Perkins, 1997; Perkins, Meilman, Leichliter, Cashin, \& Presley, 1999; Schlesselman et al., 2011). Perkins (2002) elucidates this phenomenon by stating, "Faculty and staff who are also 'carriers' of the misperception may [emphasis added] inadvertently add to the problem by reinforcing students' notions that most students drink much more heavily than is the 
case as they communicate this misperception in casual conversation" (p. 169). Furthermore, Perkins and Craig (2003) suggest that this behavior by instructors in the classroom could unintentionally encourage students to drink alcohol who otherwise had no intention to do so. However, both these insights are speculative, with no basis in exploratory or empirical research; the direct influence of faculty members on descriptive and injunctive drinking norms is underresearched in the instructional communication field. Additionally, there has been little research done on the exact impact, if any, faculty has on student alcohol use (Perkins, 2002a) or the impact that instructor discussion of alcohol in the classroom has on students' perception of their teacher. Thus, an exploratory study was necessary to research the potential effects of instructors discussing alcohol in the classroom. 


\section{CHAPTER III: STUDY ONE - QUALITATIVE STUDY}

The communication field has thus far only tangentially studied instructors mentioning alcohol in the university classroom. Teachers discussing alcohol in the classroom has been examined while scholars have researched other instructional communication phenomena such as instructor self-disclosure and humor (Borzea \& Goodboy, 2016; Frymier, Wanzer, \& Wojtaszczyk, 2008); however, the instructional communication discipline has yet to investigate this behavior on its own. Consequently, the method of Study One was exploratory in nature and designed to be the foundation for future instructional communication investigation. The qualitative study sought to undercover how students have experienced their instructors discussing alcohol in the classroom, how they determined the appropriateness of this behavior, whether this behavior resulted in a positive or negative change in their perception of the instructor, and whether there was a relationship between perceived appropriateness of the behavior and self-reported positive or negative change in their perception of the instructor. In order to investigate these questions more thoroughly, the following research questions were proposed:

$\mathrm{RQ}_{1}$ : How do instructors discuss alcohol in the classroom?

$\mathrm{RQ}_{2}$ : How do students determine if the instructor discussion of alcohol is appropriate or inappropriate?

$\mathrm{RQ}_{3}$ : Do students' perception of their instructor change after discussion of alcohol in the classroom? If so, do their perceptions change positively or negatively?

$\mathrm{RQ}_{4}$ : How is appropriateness or inappropriateness related to a positive or negative change in perception? 


\section{Qualitative Method}

\section{Data Collection}

Questionnaire. To understand the students' perspective of instructor discussion of alcohol in the classroom the first study took an emic approach to answering the research questions. Mack, Woodsong, MacQueen, Guest, and Namey (2005) recommend that exploratory researchers utilize open-ended questions to obtain responses that are "meaningful and culturally salient to the participant... [as well as] rich and explanatory in nature" (p. 4). Therefore, an openended questionnaire was developed in an attempt to understand students' experiences with their college instructor(s) discussing alcohol in the classroom. The questions asked participants (1) what the instructor said about alcohol, (2) how the class responded, (3) how old they estimated their instructor was, (4) whether the instructor's mention of alcohol in the classroom changed the participant's perception on their instructor, (5) whether the participant believed the instructor's discussion of alcohol was appropriate, and (6) whether they felt that instructor's mention of alcohol in the classroom was related to casual drinking, binge drinking, or in a different context. Additionally, participants provided demographic data, including, age, race, gender, religious affiliation, and their highest level of education obtained.

Sampling. College students from a midsized public Midwestern university were offered the opportunity to participate in the study via an online communication research portal. Additionally, invitations to take part in the survey were emailed to students using a universitywide listserv. Some participants received extra credit in their communication class for participating. Although the survey was available to all students at the university through the communication research portal, criterion sampling was used to ensure that the only students allowed in the study were those who had experienced an instructor mentioning alcohol in the 
classroom. Specifically, as a condition of taking part in the study, participants were asked if they could recall a situation where a college instructor discussed alcohol in the classroom. Those who could not recall an example were rejected from the study. All participants were assured confidentiality and asked to give informed consent.

Demographics. A total of 137 participants completed the online survey in full, all of whom were current or former college students. The sample was $75.45 \%$ female and $24.82 \%$ male, with one participant choosing not to disclose their gender identity. Those surveyed were White (81.75\%), Hispanic/Latino (7.30\%), African American (3.65\%), Asian/Pacific Islander (1.46\%), Native American (0.73\%), Middle Eastern (0.73\%), and mixed race $(3.65 \%)$, with one participant choosing not to disclose their racial identity. The age of participants ranged from 1851 years old, with a mean of 21.5 years of age $(S D=4.97)$.

\section{Data Analysis}

All research questions were unitized, coded, and categorized following guidelines provided by Strauss and Corbin (1998). Research questions one and two were coded thematically and research questions three and four were coded using a priori categories. Additionally, Lincoln and Guba (1985) suggest testing referential adequacy when analyzing qualitative data, whereby a researcher "earmark[s] a portion of the data to be archived - not included in whatever data analysis may be planned - and then recalled when tentative findings have been reached... to test the validity of the conclusions" (p. 313). Referential adequacy was used as a means to test the reliability and validity of the emergent categories (Lincoln \& Guba, 1985).

Research question one. To address RQ1, the participant's responses to the prompt "Please describe your experience(s) with instructor(s) discussing alcohol or alcohol use in the college classroom" were separated into units for coding. Some participants provided multiple 
examples; therefore, each unit consisted of one instance where the participant recalled an instructor discussing alcohol in the classroom. Thus, once the data were unitized, there was a total of 166 specific examples of instructor discussion of alcohol in the classroom provided by the 137 participants. In order to test referential adequacy, approximately one-fourth of the data ( $n$ $=40)$ was sequestered for later coding.

Following instructions for coding qualitative data provided by Strauss and Corbin (1998), the remaining units $(n=126)$ were then coded. Once the individual units were coded, axial coding was employed to group the codes found during open coding into categories and subcategories (Strauss \& Corbin, 1998). Axial coding resulted in preliminary findings regarding how students have experienced their instructors discussing alcohol in the classroom. The categories and subcategories determined during axial coding were then checked against the 40 units set aside to test referential adequacy. The units sequestered to test referential adequacy fit into the previously determined categories and subcategories. Thus, referential adequacy was achieved, and the categories and subcategories were proven to be valid reflection of the participants' experiences (Lincoln \& Guba, 1985).

Research question two. To answer RQ2, the respondents' answers to the question “Did you believe that the instructor(s) discussing alcohol was appropriate? If so, why? If not, why not?" were analyzed. During unitizing, each answer was considered to be one unit. One respondent failed to respond to the question, leaving 136 units for analysis. Thirty-four units were sequestered to check referential adequacy (Lincoln \& Guba, 1985). Each of the remaining units $(n=102)$ was then categorized to either be (1) perceived as appropriate or (2) perceived as inappropriate. Then, each of these categories was coded and categorized using axial coding (Strauss \& Corbin, 1998). Subcategories were determined through axial coding to explain how 
the participants determined if the instructor discussion of alcohol was appropriate or inappropriate (RQ2). The subcategories for the instructor discussion of alcohol being (1)

perceived as appropriate were separated into mentions that were (1a) relevant to students or (1b) relevant to class. The responses that indicated the instructor discussion of alcohol as (2) perceived to be inappropriate were divided into teacher mentions that were either (2a) irrelevant to students or (2b) irrelevant to class.

Referential adequacy was tested by categorizing the sequestered raw data $(n=34)$ into these categories. All of the responses were perceived to be either appropriate or inappropriate during the referential adequacy check and the subcategories identified during the initial analysis reflected the responses in the raw data. The sequestered units fit into the initial categories and subcategories; thus, the validity of these categories was confirmed (Lincoln \& Guba, 1985).

Research question three. To answer this research question, the data were categorized as either the participant indicating a change in perception of instructor or participant indicating no change in perception of instructor. Frequency and proportion of the categories were then calculated. Those respondents who indicated that the instructor discussion of alcohol resulted in a change in their perception of the instructor were then categorized as either a (a) positive change in perception or (b) negative change in perception.

Research question four. RQ4 was addressed by analyzing the categorized data from in RQ2, (1) perceived as appropriate and (2) perceived as inappropriate, and combining them with the categorized data from RQ3 to develop four new categories: (a1) positive-appropriate, (b1) negative-appropriate, (a2) positive-inappropriate, and (b2) negative-inappropriate (see Figure 1). One participant's response stated that the instructor discussion was appropriate but did not provide information to determine whether the behavior affected their perception of the instructor, 
so their response was not used for further analysis. The proportion and frequency of these categories were then calculated.

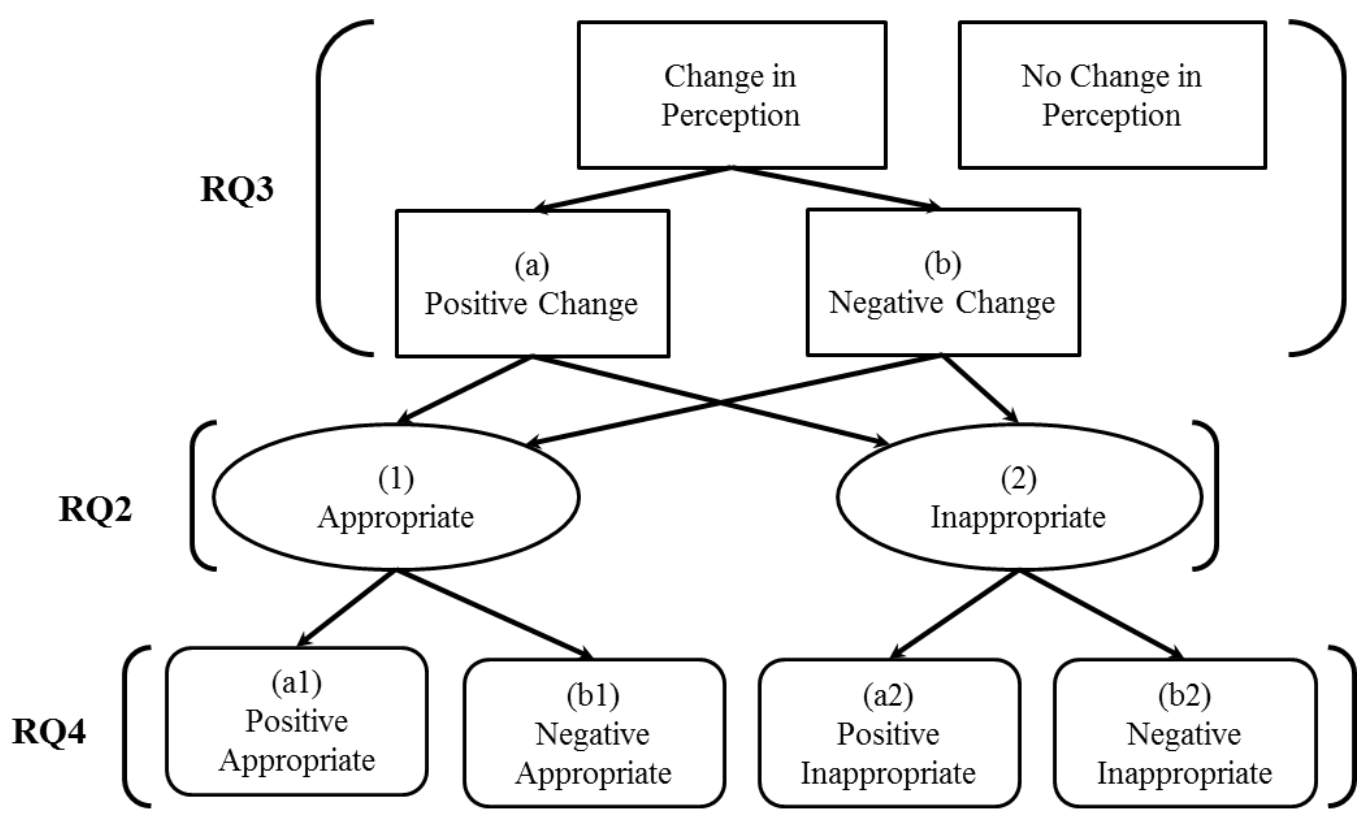

Figure 1. Model of Research Question Four. Each of the participants' responses from RQ2 was analyzed in conjunction with the responses from RQ3 to determine how appropriateness affected students' self-reported positive or negative change in their perception of the instructor following the instructor discussing alcohol in the classroom (RQ4).

\section{Qualitative Research Results}

\section{How Instructors Discuss Alcohol in the Classroom}

(1) Student alcohol use as normative. In response to the first research question, regarding how instructors talk about alcohol in the classroom, a majority $(62.65 \%, n=166$; see Table 1) of the responses indicated that when instructors discussed alcohol in the classroom, they mentioned it in regards to (1) student alcohol use as a normative behavior, creating the first category. This category was developed with the understanding that mentioning alcohol in the classroom casually may portray "alcohol consumption as a social norm that is supported by the faculty and, in many cases, by the institution" (Schlesselman et al., 2011, p. 240). Participants' 
descriptions of instructor discussion of alcohol in the classroom revealed that it was frequently discussed as a behavior in which students regularly engage. This finding is important, as Perkins (2002) suggests that university faculty can serve as an important reference group for students and that "the course of behavior most commonly taken is typically in accordance with normative directives of "reference groups"” (p. 164). Three subcategories provided "more precise and complete explanations about [this] phenomena" (Strauss \& Corbin, 1998, p. 124). The subcategories were identified as instructors (1a) discussing student drinking in the past or future, (1b) advocating for safe/responsible student drinking, and (1c) joking about students drinking, all of which are casual mentions of alcohol by a faculty member in the classroom with the potential to perpetuate the idea of student alcohol consumption as a social norm (Schlesselman et al., 2011). The following section provides examples from the participant's responses to justify these subcategories.

(1a) Discussing student alcohol use in past or future. When instructors discussed student drinking in the classroom as normative, participants most frequently $(51.92 \%, n=104)$ reported that it was mentioned in the context of the students using alcohol in the past or the future. Participants' responses indicated that they had experienced instructors reinforcing student drinking as a norm by assuming their students imbibed in the past. As one participant stated, "A professor of mine brings up the students going to the bars, having hangovers, and the idea of college kids drinking in their lecture.” Another respondent recalled a time when an instructor "asked if we were tired because we hit the pub... it was a Thursday morning and the pub is $1 / 2$ price Wednesday's." This finding is disconcerting, as "faculty norms concerning academic class expectations in general may be an important component of [alcohol] prevention" (Perkins, 2002a, p. 166). In this quote, Perkins suggests that instructors need to set academic norms that 
work to prevent student alcohol abuse. These findings show that some instructors reinforce the stereotype that college students abuse alcohol, which could be perpetuating the norm that engaging in such behavior is routine. Additionally, participants' responses indicated that their instructors reaffirmed student alcohol use as a norm by referencing their student drinking in the future. As one participant stated:

Whenever I have classes towards the end of the week, teachers make sarcastic comments such as, "I know you all would much rather be drinking a beer" or "I know you all can't wait to go to the Pub II."

Other respondents provided examples where instructors anticipated their students drinking over homecoming weekend and moved the date of an exam or assignment to facilitate students spending their weekend partying instead of studying.

(1b) Advocating safe/responsible student alcohol use. Of the units describing instructor discussion of alcohol in the classroom as normative, $28.85 \%(n=104)$ of the responses were related to instructors promoting safe and responsible alcohol consumption by students. Although advocating for students to drink responsibly and safely outside of the classroom is wellintentioned, it also reinforces the norm that students use alcohol irresponsibly and need to be reminded to stay safe.

Participants reported that their instructors gave them specific guidelines on how to drink alcohol safely. For example, one respondent recounts an instance where their instructor offered specific advice on drinking alcohol during the upcoming holiday weekend.

[We were told] to be safe over Halloween weekend if we were going to drink over the weekend, which the instructor knew was inevitable, [so] instead of lecturing us on not 
drinking the instructor told us to use the buddy system, take a[n] Uber, or have a [designated driver].

In this statement, it is clear that the student believes his or her instructor has the perception of student alcohol use as normative behavior, and the instructor is reinforcing the norm by encouraging students to drink in a responsible manner. Other participants recalled their instructors giving vaguer advice, such as, "Be safe and don't drink too much this weekend" or "My instructor said to make good choices and to [be] responsible when drinking." Finally, some participants offered examples where their instructor cautioned against binge drinking, such as reminding their students to drink in moderation.

(1c) Joking about student alcohol use. The third most frequent $(19.23 \%, n=104)$ example of instructors reinforcing the norm of student alcohol use was via the instructor telling a joke about their students drinking. This subcategory overlaps to some extent with category $1 \mathrm{a}$, as some of the reported jokes were related to students drinking alcohol in the past or future; however, enough of the responses indicated that instructors discussed alcohol in a humorous way $(n=20)$ to constitute the development of an additional subcategory. One such example occurred when a participant recalled that their instructor "jokes about the class not doing assignments because the class is busy drinking. He [also] joked that Homecoming and Halloween were just excuses for drinking." Another respondent appeared to have a similar experience when they reported that "instructors have joked when students are sick that they had too much to drink."

(2) Alcohol in the curriculum. The second major category $(19.88 \%, n=166)$ identified in the data was alcohol being discussed by instructors as part of a formal lesson or used as an example to illustrate a course concept. Participants reported alcohol discussion in the context of the course curriculum. This category is perhaps the least surprising theme to emerge from the 
data, as human-made alcohol has empirically been proven to exist since at least 7,000 BCE (McGovern et al., 2004) and, as such, has had doubtless impacts on humanity worthy of study academia. As one participant stated, "We had an entire unit on alcohol in a cultural context for my anthropology class." Furthermore, instructors used alcohol in the classroom as a way to illustrate course concepts; which a respondent depicted by providing the following example, We were comparing normal and inferior goods in my economics class so the instructor used the example that Natty Light was an example of an inferior good and as your income increases, you tend to buy more normal goods such as Bud Light.

Although alcohol education in university curricula is an unsurprising finding, the fact that only $20 \%$ of participants' experiences with instructor discussion of alcohol in the classroom were related to course concepts is notable.

(3) Instructor personal alcohol use behaviors. Finally, $15.06 \%(n=166)$ of participants' responses indicated that students experienced instructors discussing their personal alcohol consumption behaviors. Participants' examples ranged from a casual mention of personal alcohol use by an instructor, such as when a respondent stated, "[The instructor] briefly mentioned a time when he got drunk, an embarrassing moment for him, I guess;" to more overt, aggressive mentions of personal alcohol use. As one participant recalled,

In undergrad, I had an instructor who would start each class by opening a can of Diet Pepsi and pouring it into a pint glass. Almost every time, he would remark that he wished he were drinking a beer instead of a soft drink. This class met at 8 a.m. Another participant provided a similarly forward example by stating, "I can't remember exactly what she said, but she made a reference about putting alcohol in her morning coffee because she was having a bad day and it was only 10am.” While not all instructor mentions of personal 
alcohol use were as overt as these two examples, five responses in this category recounted experiencing their teacher claiming to "need a drink." Other respondents discussed their instructor mentioning alcohol use in the past tense, such as drinking when they were in college. Finally, some participants recalled their instructor mentioning alcohol use in the future tense, as exemplified by this respondent's quote of his or her instructor, "I'll be watching the Cubs game in downtown Chicago at one of the bars, pretty sure I won't be able to walk straight afterwards." In this category, participants consistently provided some of the richest and most vivid recollections of instructors discussing alcohol in the classroom, potentially suggesting that when instructors violate student expectations by self-disclosure their own drinking behaviors in the classroom, the memory remains significantly more salient than other instructor mentions of alcohol.

Table 1

Emergent Themes from Thematic and Axial Coding of Responses

\begin{tabular}{lccc}
\hline \multicolumn{1}{c}{ Theme } & $n$ & Proportion of $n$ & Frequency \\
\hline Student Alcohol Use as Normative & 166 & $62.65 \%$ & 104 \\
$\quad$ Student past/future alcohol use & 104 & $51.92 \%$ & 54 \\
$\quad \begin{array}{l}\text { Advocating for safe student } \\
\text { alcohol use }\end{array}$ & 104 & $28.85 \%$ & 30 \\
$\quad$ Joking about student alcohol use & 104 & $19.23 \%$ & 20 \\
Alcohol in the Curriculum & 166 & $19.88 \%$ & 33 \\
Instructor Discussing Personal & 166 & $15.06 \%$ & 25 \\
Alcohol Use & 166 & $2.41 \%$ & 4 \\
\hline Uncategorizable & & & \\
\hline
\end{tabular}




\section{Appropriateness of Instructor Discussion of Alcohol}

In answer to the second research question investigating how students determine if the instructor discussion of alcohol is appropriate or inappropriate, $76.47 \%(n=136)$ of the participants' responses indicated that they perceived the instructor discussion as (a) appropriate, and $15.44 \%$ perceived the discussion alcohol as (b) inappropriate. Eleven of the participants $(8.09 \%, n=136)$ either chose not to answer or gave responses that were too vague to be categorized; these responses were eliminated from further analysis as there was not enough information to draw any conclusions. The (1) perceived as appropriate category is made up of two subcategories, (1a) relevant to students and (1b) relevant to class. The perceived as (2) inappropriate category consists of subcategories (2a) irrelevant to students and (2b) irrelevant to class (see Table 2).

Table 2

Relationship between Relevance of Teacher Mention of Alcohol and Perceived Appropriateness

\begin{tabular}{lccc}
\hline \multicolumn{1}{c}{ Perception } & $n$ & Proportion of $n$ & Frequency \\
\hline Appropriate (1) & 136 & $76.47 \%$ & 104 \\
Relevant to Students (1a) & 104 & $63.46 \%$ & 66 \\
Relevant to Class (1b) & 104 & $36.54 \%$ & 38 \\
Inappropriate (2) & 136 & $15.44 \%$ & 21 \\
Irrelevant to Students (2a) & 21 & $33.33 \%$ & 7 \\
Irrelevant to Class (2b) & 21 & $66.67 \%$ & 14 \\
Uncategorizable & 136 & $8.09 \%$ & 11 \\
\hline
\end{tabular}




\section{(1) Perceived as appropriate.}

(1a) Relevant to students. Of the participants who perceived the instructor discussion of alcohol as appropriate, $63.46 \%(n=104)$ attributed the appropriateness of the comment to the fact that it was (1a) relevant to the students. For example, many participants mentioned that the comment was appropriate for them because they were of legal drinking age. As one respondent illustrated, "Since both of my classes are primarily juniors and seniors who are of drinking age, I felt that the comments were appropriate;" while another stated, "Yes, [it was appropriate] because we are in college and we all drink, even the professors and instructors. It's not a taboo thing, so it isn't something that turned me off to the instructor." Additionally, if the instructor showed concern for the students by advocating for safe alcohol use, it was perceived as an appropriate mention of alcohol. The commonality between all the responses in this subcategory was that the students perceived the instructor discussion of alcohol to be relevant to them.

(1b) Relevant to class. Respondents also attributed the appropriateness of the instructor discussion of alcohol to the comment being (1b) relevant to class $(36.54 \%, n=104)$. As one participant explains, instructors mentioning alcohol was deemed appropriate if it was part of the curriculum for the course, "We took an anthropological view on alcohol consumption from the time of its creation to modern day college drinking." Additionally, if the mention of alcohol was used as an example it was perceived as appropriate, as illustrated by one participant who stated,

"It was [appropriate] at the time. He was trying to use it as an example to create a math question for the class so they could understand the lesson better." Finally, participants indicated that jokes and humorous anecdotes about alcohol related to course content were perceived as appropriate. Overall, a majority of respondents indicated that they perceived the instructor discussion of alcohol to be appropriate, with the most cited reasons being the relevance alcohol to the students 
or the class. However, one-eighth of the responses believed their experience of an instructor discussing alcohol in the classroom was inappropriate.

\section{(2) Inappropriate.}

(2a) Irrelevant to students. Approximately 33.33\% $(n=21)$ of "inappropriate" responses indicated that the reason they perceived the mention of alcohol by an instructor to be inappropriate was due to it being irrelevant to them. For example, one participant explains,

I don't think the professor should discuss it. While it is inevitable that most college students drink, most people in these classes are under the legal drinking age of 21 , and therefore it would seem as if a professor would be advocating drinking, which is not right.

Another participant describes a similar experience: "[It was not appropriate] because first of all we are an alcohol- and drug-free campus, and we are all underage_-it just felt uncomfortable.” The theme of underage students perceiving the instructor discussion of alcohol in the classroom as inappropriate was echoed by other participants. The respondents repeatedly acknowledged the inappropriateness of instructors discussing alcohol with students who are legally forbidden to drink because the instructor is implicitly normalized underage drinking.

(2b) Irrelevant to class. Finally, $66.67 \%(n=21)$ of the respondents who suggested that the discussion of alcohol was "inappropriate" said that it was so because it was unrelated to class. Students offered examples such as, "I don't believe it's appropriate for the classroom. Time in the classroom is time for instruction," and "I do not believe it was appropriate because it was off topic from our lecture." Another frequently cited example of the alcohol discussion being irrelevant to class was the instructor telling a joke. This category is consistent with Wanzer et al.'s (2006) research, which found that some college students identify humor related to drinking 
alcohol as offensive and inappropriate. Students appear to perceive their instructors discussing alcohol in the classroom as inappropriate if it distracts or detracts from the course material.

\section{Change in Perception of Instructor following Discussion of Alcohol}

All of the data fit into the categories and subcategories developed prior to coding. In response to RQ3, approximately $65.91 \%(n=132)$ of respondents did not have their perception of the instructor changed. However, 34.59\% $(n=132)$ of the participants had a change in their perception of the instructor following the instructor discussing alcohol in the classroom (see Table 3). Of those who had a change in their perception $(n=45), 73.33 \%$ had a positive change in their perception of the instructor and $26.67 \%$ reported a negative change in perception (see Table 3).

Table 3

Change in Perception of Instructor

\begin{tabular}{crcc}
\hline Perception & $n$ & Proportion of $n$ & Frequency \\
\hline Change & 132 & $34.09 \%$ & 45 \\
Positive & 45 & $73.33 \%$ & 33 \\
Negative & 45 & $26.67 \%$ & 12 \\
No Change & 132 & $65.91 \%$ & 87 \\
\hline
\end{tabular}

\section{Relationship between Appropriateness and Change in Perception of Instructor}

In response to RQ4, a majority of the participants $(66.67 \%, n=45$; see Table 4$)$ who found the discussion of alcohol to be appropriate had a positive change in their perception of the instructor (a1). For example, a participant who believed the instructor discussion of alcohol was appropriate because it was relevant to the students also indicated a positive change in perception by stating, "I thought that the instructor was a little more down to earth and relatable to the 
students." The response that an appropriate instructor discussion of alcohol leads to the instructor seeming more relatable was repeated by many participants. A perception that the instructor is more relatable could enhance instructor approachability, which has been shown to increase student academic confidence as well as motivate students extrinsically and intrinsically (Komarraju, Musulkin, \& Bhattacharya, 2010). Additionally, a more positive perception of an instructor could increase student-teacher rapport (Frisby \& Housley Gaffney, 2015), which has been shown to increase student "affective learning, state motivation, and satisfaction" (Frisby \& Myers, 2008, p. 30).

Table 4

Relationship between Appropriateness and Change in Perception of Instructor

\begin{tabular}{cccccc}
\hline Perception & $n$ & $\begin{array}{c}\text { Proportion of } n \\
\text { Appropriate }\end{array}$ & $\begin{array}{c}\text { Frequency } \\
\text { Appropriate }\end{array}$ & $\begin{array}{c}\text { Proportion of } n \\
\text { Inappropriate }\end{array}$ & $\begin{array}{c}\text { Frequency } \\
\text { Inappropriate }\end{array}$ \\
\hline Change & 45 & $71.11 \%$ & 32 & $28.89 \%$ & 13 \\
Positive $^{\mathrm{a}}$ & & $66.67 \%$ & 30 & $6.67 \%$ & 3 \\
Negative $^{\mathrm{b}}$ & & $4.44 \%$ & 2 & $22.22 \%$ & 10 \\
No Change & 87 & $85.06 \%$ & 74 & $14.94 \%$ & 13 \\
\hline
\end{tabular}

Note. ${ }^{\mathrm{a}-\mathrm{b}}$ The proportions in the positive and negative rows were calculated by dividing either the positive-appropriate, positive-inappropriate, negative-appropriate, or negative-inappropriate frequency by the number of respondents who indicated a change in perception $(n=45)$.

Far fewer respondents $(4.44 \%, n=45)$ indicated a negative change in perception following an appropriate instructor discussion of alcohol (b1). A respondent who indicated that an appropriate discussion of alcohol resulted in a negative change in perception elucidated that it was caused by the instructor assuming "that my illness was related to alcohol. This was despite me saying explicitly that it wasn't." The respondent believed the discussion of alcohol to be 
appropriate because it was infrequently mentioned, but confessed that the instructor immediately attributing his or her absence due to illness as a result of overindulging in alcohol (which the respondent insisted was not the case) was "annoying."

Approximately $6.67 \%(n=45)$ of respondents who had a positive change in their perception of the instructor perceived the instructor discussion of alcohol in the classroom to be inappropriate (a2). One participant's responses explained that although the discussion of alcohol was inappropriate due to its irrelevance to class, it did have a positive impact on the student's perception of the instructor because it made them seem "a little bit cooler." Another participant felt that while alcohol used as a joke was inappropriate, it resulted in a positive change in their perception of the instructor because it was humorous to the student.

A larger proportion of respondents $(22.22 \%, n=45)$, who indicated a negative change in their perception of the instructor, reported that they considered the discussion of alcohol to be inappropriate (b2) (see Table 4). As one participant succinctly articulated, "I think she says some things that are inappropriate. She lost some of my respect especially since she assumes we all drink, and I do not." Other respondents seemed to indicate that their perception of the instructor was negatively affected following an inappropriate discussion of alcohol since the instructor appeared to condone the students drinking alcohol. Finally, participants mentioned their instructors joking about alcohol use as having a deleterious effect on their perception of the instructor.

Overall, respondents who indicated the instructor discussion of alcohol as appropriate more frequently had a positive change in their perception of the instructor. Additionally, those who perceived the instructor discussion of alcohol as inappropriate reported a negative change in perception of their instructor more frequently. The findings of this study suggest that the 
perceived appropriateness of the discussion of alcohol is an important indicator of whether the mention of alcohol will cause a positive or negative change in the perception of the instructor.

\section{Qualitative Discussion}

\section{Summary of Findings}

Study One demonstrated that students have experienced their instructors discussing alcohol in the classroom. In fact, participants recounted their experience with surprising detail, frequently remembering specific minutiae, especially when the experience consisted of the instructor discussing their own drinking behavior. Interestingly, this finding contradicts the research of Vangsness Frisch (2016), who found that students frequently could not recall a time when their instructor discussed alcohol in the classroom.

The primary goal of this study was to determine how students have experienced their instructors discussing alcohol in the classroom. At an institution that exists to educate people, the expectation is that students would primarily report experiencing their instructors discussing alcohol in an informative context. However, this study found that only one-fifth of the students reported instructors discussing alcohol in the classroom in an educational manner. Instead, a majority of participants' responses indicated that when students experience instructors discussing alcohol in the classroom it is mentioned in a way that reinforces the norm of student alcohol use $62.65 \%$ of the time $(n=166)$.

Of those that experienced alcohol being discussed in the classroom as normative, many participants experienced their instructor discussing student past or future drinking behaviors, such as anticipating their students drinking over an upcoming holiday. This finding aligns with research done by North Dakota State University (2014), where 12.2\% of 1,076 faculty members surveyed responded that they "often," "occasionally," or "rarely" avoid scheduling an exam near 
large social events because they assume their students will be drinking. The findings of that study and the present study suggest that some university instructors do plan exams around students drinking behavior, which could reinforce student alcohol use as normative behavior in college. Specifically, Perkins and Craig (2003) posit that instructors who move assignments in anticipation of their students' excessive drinking behavior cause "the minority of students who do drink heavily in ways that affect their academic participation [to] actually [be] 'enabled' in their behavior by the faculty member's misperception of the student norm" (p. 50).

Additionally, instructors advocated for students to consume alcohol safely. The emergence of this subcategory was unsurprising, as "many faculty view student alcohol misuse as a significant problem, are quite interested in the welfare of their students, and are concerned about the impact of drinking" (Perkins, 2002a, p. 164). Furthermore, Heyne (1984) found that university instructors are willing to help mitigate the issue of alcohol abuse on campus.

Participants also indicated that their instructors joked about student alcohol use. This finding is consistent with the results of previous studies regarding instructors joking about alcohol in the classroom, such as a survey of 1,076 faculty members, where $29.4 \%$ of instructors admitted to joking about student alcohol use (North Dakota State University, 2014). Additionally, Wanzer et al.'s (2006) study of instructor use of humor in the classroom found that $13 \%$ of students reported experiencing an instructor joking about alcohol use. Instructors who joke about their students abusing alcohol to such an extent that it directly affects their academics could perpetuate the misconception that this is normative behavior in college, as Lederman and Stewart (2005) found that 58\% of the students surveyed thought that faculty joking about student excessive alcohol consumption in the classroom reinforced student alcohol use as normative. 
Overall, these findings of the present study appear to confirm the speculation of earlier researchers that students may experience their instructor perpetuating the norm of drinking alcohol in higher education (Lederman \& Stewart, 2005; Lui et al., 2013; Perkins, 2002a; Perkins \& Craig, 2003; Stewart et al., 2002).

Furthermore, $15 \%$ of students reported their instructors discussing personal alcohol use behaviors in front of their students. Students reporting an experience where their instructor disclosed personal alcohol consumption aligns with the results of the North Dakota State University (2014) survey, which found that $20 \%$ of faculty surveyed discussed their personal alcohol use in front of students. Participants almost universally found instructor discussion of their personal alcohol use to be inappropriate. This finding is similar to previous instructional communication research, which has shown that instructor disclosure of personal alcohol use in the classroom is considered inappropriate by students (Nunziata, 2007) and can damage teacher credibility (Hosek \& Thompson, 2009).

Another key finding of this study was that a majority of participants perceived their instructor discussing alcohol in the classroom as appropriate. Students appeared to determine the appropriateness of the discussion of alcohol based on its relevance to class or relevance to themselves. Instructor discussion of alcohol was considered inappropriate if it was not relevant to the course material or to the students. The present study also investigated the effect of appropriateness on a positive or negative change in perception of the instructor. According to the participants' responses, instructor discussion of alcohol in the classroom was far more likely to result in a positive change in perception. Conversely, those mentions of alcohol perceived as inappropriate proved to be more likely to harm the student's perception of their instructor. This finding echoes previous research on instructor self-disclosure (Hosek \& Thompson, 2009) and 
instructor humor (Wanzer et al., 2006), which found that perceived appropriateness was an important factor in students ascribing a positive or negative attribution to their instructor's behavior.

Finally, and perhaps most importantly, the findings of the present study suggest that there are two contexts in which instructors should perhaps avoid mentioning alcohol. First, an instructor's personal alcohol consumption behaviors should not be discussed in the classroom; and second, the topic should not be discussed as normative in a classroom where the students are under the legal drinking age. However, there is an exception to the former context; as research by White et al. (2010) has demonstrated that instructors discussing the harms associated with alcohol consumption through curriculum infusion can result in "significantly less negative consequences related to drinking than their counterparts [who did not receive information via curriculum infusion]" (p. 515) regardless of the age of the students.

\section{Strengths and Limitations}

The strongest asset of the present study was its use of students' own experiences to explore instructor discussion of alcohol in the classroom. This research is a useful way to begin investigating a phenomenon that is common in the university classroom, yet rarely studied in academia. This exploratory study served as a solid foundation upon which other researchers can begin to more thoroughly investigate the effects of instructor discussion of alcohol on students' perception of peer alcohol use as normative, their instructor as an individual, and the classroom environment. Additionally, this research could be useful for college instructors. Instructors should be cognizant that, although their discussion of alcohol in the classroom can have a positive effect on how their students perceive them, it must be mentioned in a manner that is relevant to the students or relevant to the class. Furthermore, instructors should be wary that 
although discussing alcohol in the classroom may be perceived by some students as appropriate, it can perpetuate the norm that drinking alcohol in college is a normative behavior.

As the present study was conducted by a single researcher, one of the limitations of the research was an inability to confirm the validity of categories through an intercoder reliability check. Although referential adequacy was utilized, the trustworthiness of the results of this study could have been further bolstered through triangulation to verify the validity of the findings (Lincoln \& Guba, 1985). Additionally, this study did not specifically examine the relationship between the participants' ages and the perceived appropriateness/inappropriateness of the mention of alcohol in the classroom. The discussion of alcohol may be seen as irrelevant (and therefore inappropriate) to students who are under the legal drinking age, yet relevant to those who are old enough to legally consume alcohol. The mean age of the participants of this study was 21.5 years old, which could explain why such a large percentage of respondents reported the discussion of alcohol as perceived to be appropriate.

\section{Conclusion}

The findings of the present study demonstrate that instructors do casually discuss alcohol in the classroom, and it has the potential to have both positive and negative impacts on the perceptions their students have of them, depending on the perceived appropriateness. As an exploratory study, this research offers a starting point for further research to investigate casual instructor discussion of alcohol in the classroom. Using these findings, future researchers can explore how this behavior affects the relationship between the student and their teacher and whether mentioning alcohol in the classroom perpetuates college drinking as a norm. 


\section{CHAPTER IV: STUDY TWO - QUANTITATIVE STUDY}

As a direct follow-up study to Study One, Study Two seeks to explore how the context an instructor discusses alcohol in the classroom affects a student's relationship with, and perception of, their teacher. Specifically, the present study examines university students' descriptive (perception of how much and how frequently one's peers consume alcohol) and injunctive drinking norms (perceived appropriateness of alcohol use; Crawford \& Novak, 2010), as well as how mentioning alcohol in a university classroom affects student-teacher rapport, homophily, and instructor credibility.

\section{Literature Review}

\section{Instructor-Student Rapport}

According to Frisby and Housley Gaffney (2015), "Rapport is an overall perception of the instructor [that] encompasses the belief that there is a mutual, trusting, and prosocial bond, including a personal connection and enjoyable interactions" (p. 341). Instructor-student rapport was initially researched solely in terms of nonverbal communication to increase rapport (LaFrance, 1979; LaFrance \& Broadbent, 1976); however, contemporary instructional communication (Frisby \& Martin, 2010) and psychological (Ryan, Wilson, \& Pugh, 2011; Wilson, Ryan, Pugh, 2010) researchers study rapport more holistically. Some communication scholars have identified the dimensions of instructor-student rapport from research done by Gremler and Gwinner (2000) on customer-employee service relationships (Frisby \& Housley Gaffney, 2015; Frisby \& Martin, 2010; Frisby \& Myers, 2008). These scholars define the two dimensions of rapport as the "enjoyable interaction dimension, which is comprised of feelings of liking and positivity in the relationship and [the] personal connection dimension, which is evidenced by strong affiliation, a bond, understanding, and mutual feelings within the 
relationship" (Frisby \& Myers, 2008, p. 27). Benson, Cohen, and Buskist (2005) took a different methodological approach by conceptualizing rapport using denotative definitions provided by two dictionaries, "a relationship; especially one of mutual trust or emotional affinity" (American Heritage Dictionary, 1991, p. 1026) and "a relation; connection; an especially harmonious or sympathetic relation" (Random House Dictionary, 1987, p. 1601). Wilson et al. (2010) developed a professor-student rapport scale by offering students a basic definition of the term and asking students for their opinion of what constitutes rapport between a student and a professor, how it is established, and how it could be measured. Wilson et al. used students' feedback to develop a measure of student-teacher rapport; this scale was found to be satisfactorily reliable and valid after further testing by Ryan et al. (2011).

Rapport in the classroom has several positive outcomes. For example, previous research found that "teachers who establish rapport with their classes are likely to have students who attend class, pay attention during class, and enjoy the subject matter," as well as "lay the groundwork for interactions with teachers during office hours or through e-mail" (Benson et al., 2005, p. 238). Frisby and Martin (2010) similarly found that rapport increases participation, and follow-up research linked student perception of positive rapport to enhanced student cognitive learning (Frisby \& Housley Gaffney, 2015). Additionally, Grantiz, Koernig, and Harich (2008) found that faculty see rapport as having the potential to enhance learning, as well as to increase student attention, involvement, participation, and comfort.

Instructor behavior. Prior research on instructor discussion of alcohol in the classroom has suggested that the behavior of the instructor may have an impact on rapport. For example, Perkins (2002) notes that faculty are generally interested in the wellbeing of their students and concerned about the impact that alcohol consumption has on their students' school work. If 
instructors convey this sentiment in the classroom, the sense that they care for their students could "be considered [a] rapport-building [technique] leading to enjoyable interactions and personal connections with students" (Frisby \& Myers, 2008, p. 28). Benson et al. (2005) and Murphy and Rodríguez-Manzanares (2012) concurred that instructors demonstrating concern and caring for their students can cause rapport to develop. Furthermore, expressing concern for students' safety could potentially increase the prosocial bond between the instructor and their student, and therefore rapport. Research has shown that caring for students is also related to perceived instructor credibility (Finn et al., 2009), a concept which will be explicitly discussed in a subsequent section. Finally, Grantiz et al. (2008) posit that the antecedents of instructor-student rapport are approach, personality, and homophily; the relationship between the latter and instructors discussing alcohol in the classroom are detailed next.

Instructor humor. A well-documented dimension of rapport relevant to instructor discussion of alcohol is the use of humor in the classroom (Frisby \& Myers, 2008). Wanzer et al.'s (2006) study on the use of humor in the classroom found that $13 \%$ of students surveyed experienced their instructor using humor associated with drinking. This finding is unsurprising, as a North Dakota State University (2014) study found that $40 \%$ of instructors surveyed acknowledged that they joke about alcohol in the classroom. Although Wanzer et al. (2006) and Frymier et al. (2008) advise against instructors using humor related to alcohol in the classroom, jokes or anecdotes about alcohol that students perceive as appropriate could result in the instructor and the learning environment being perceived positively (Banas, Dunbar, Rodriguez \& Liu, 2011) and thus increase student-teacher rapport. 


\section{Homophily}

In the interpersonal communication discipline, homophily is defined as perceived similarity (J. C. McCroskey, Richmond, \& Daily, 1975). The concept of homophily is of interest to communication scholars because "the more similar two communicators are, the more likely they are to interact with each other" (J. C. McCroskey, Richmond, \& McCroskey, 2006, p. 31). Nunziata's (2007) research found that when instructors disclosed their personal drinking behaviors, some students perceived the instructor to be more relatable and therefore approachable. Thus, Study Two seeks to investigate if instructors discussing alcohol has a measurable impact on perceived instructor homophily.

When research on interpersonal homophily was nascent, J. C. McCroskey et al. (1975) identified four dimensions of homophily, "attitude, morality, background, and appearance" (p. 332), which were measured by a 14-item scale. However, researchers later narrowed interpersonal homophily down to two distinct dimensions: perceived similar attitudes and perceived similar backgrounds (L. L. McCroskey, McCroskey, \& Richmond, 2006). The present study will conceptualize homophily in an instructional setting by emulating Myers and Huebner's (2011) research, where "instructor homophily refers to the extent to which students consider their instructors to share similar attitudes (i.e., shared beliefs, attitudes, and values) and backgrounds (i.e., shared experiences)" (para. 4; see also J. C. McCroskey et al., 2006).

Studying instructional homophily and its implications in the classroom is vital, as "students who see themselves as similar to teachers [are] more likely to communicate with and understand their teachers, a process which is crucial to the desired outcomes in a classroom setting” (Rocca \& McCroskey, 1999, p. 309). Many instructors want to increase student participation (Rocca, 2010), and Myers et al. (2009) found that instructor background homophily 
and attitude homophily implicitly motivated students to participate in class, a finding which was confirmed in a later study by Myers and Huebner (2011).

Instructor homophily is also linked with instructor immediacy (Edwards \& Edwards, 2001; Myers et al., 2009; Powell, Hamilton, Hickson, \& Stuckey, 2001). Immediacy is defined as "an instructor's use of communicative behaviors that reduce physical and psychological distance with students in the classroom" which "can emerge in both a nonverbal and verbal form” (Myers et al., 2009, p. 125; see also Andersen, 1979). Instructors demonstrating verbal immediacy in the classroom is important, as it has been linked to student affective and cognitive learning (Gorham, 1988). Of particular interest to the present study is how homophily can impact teacher verbal immediacy, which includes instructor classroom behaviors such as the use of humor, using inclusive pronouns (e.g., "we" and "us"), and self-disclosure (Gorham, 1988). Study One found that students experienced their instructors discussing alcohol in a joking manner, and it was often perceived as appropriate. Thus, that specific construct of verbal immediacy (humor) is particularly relevant to the present study. Powell et al. (2001) succinctly describe the relationship between these variables:

Homophily positively affects attraction and thus immediacy; immediacy positively affects homophily. The more a student feels that the teacher is similar, the more the student likes the teacher, the more the teacher acts in an [sic] homophilous manner, the more the student learns. (p. 219)

While the present study will not explicitly investigate instructor immediacy behaviors, its relationship with homophily demonstrates another benefit of students perceiving their instructors to be similar to themselves. 


\section{Instructor Credibility}

Perceived credibility has multiple positive student outcomes. In their comprehensive meta-analysis of instructor credibility research in the communication discipline, Finn et al. (2009) list seven positive student outcomes resulting from perceived instructor credibility that researchers have identified (see Table 9 in Appendix A). Aristotle conceptualized credibility, ethos, as a combination of speaker character, goodwill (Freese, 1926), and intelligence (J. C. McCroskey \& Teven, 1999). In the instructional communication discipline, instructor credibility is empirically measured using three similar dimensions: competence, goodwill (caring), and trustworthiness (J. C. McCroskey \& Teven, 1999). These three dimensions and the accompanying 18-item measure have become the standard way most instructional communication scholars research teacher credibility (Finn et al., 2009). Of particular interest for the present study is the dimension of perceived instructor caring. Some students in Study One noted that they appreciated their instructor advocating safe alcohol consumption practices (e.g., using a designated driver), a behavior which demonstrates caring. The potential relationship between this instructor behavior identified in Study One and instructor credibility is explored in more detail in the following subsection. Furthermore, participants in Study One indicated that they perceived their instructor discussing personal drinking behaviors in the classroom as inappropriate. The possibility of this type of instructor self-disclosure harming instructor credibility is also discussed below.

Caring. In the aforementioned meta-analysis by Finn et al. (2009), instructor caring had the largest effect size of all the dimensions of instructor credibility. The authors explain this phenomenon and its implications by positing: 
To the extent that teachers are empathetic, understanding, and responsive to their students, and to the extent that they communicate to their students that they have their best interests in mind, such efforts are likely to enhance their students' interest in the course, their involvement in classroom activities and assignments, and ultimately, their learning. (p. 531)

Furthermore, Teven and McCroskey (1997) found evidence that perceived instructor caring is associated with perceived cognitive learning and increased affective learning in the classroom. J. C. McCroskey and Teven (1999) suggest that there are three elements of goodwill/caring: understanding, empathy, and responsiveness. Understanding, in the instructional context, can be conceptualized as an instructor knowing the ideas, feelings, and needs of their students (J. C. McCroskey \& Teven, 1999). Teven and Hanson (2004) found that explicit verbal messages demonstrating caring for students can increase perceived instructor credibility. Study Two seeks to determine whether instructors advocating for their students to practice safe alcohol consumption behaviors (see Study One) increases perceived instructor credibility, perhaps by demonstrating understanding (J. C. McCroskey \& Teven, 1999) for their students' social lives or simply by verbally exhibiting concern for the well-being of the students (Teven \& Hanson, 2004).

Self-disclosure. According to Myers and Brann (2009), instructors can establish credibility with their students by self-disclosing information that is both relevant to students and relevant to the course material. However, if students perceive the instructor self-disclosure to be negative, it may lower teacher credibility (Cayanus \& Martin, 2008). Miller, Katt, Brown, and Sivo (2014) found that negative instructor self-disclosures can have an indirect detrimental impact on instructor credibility, specifically via the competence and trustworthiness dimensions. 
One such negative self-disclosure might be instructors disclosing their personal alcohol use behaviors (Hosek \& Thompson, 2009; Nunziata, 2007; Wang, Novak, Scofield-Snow, Traylor, \& Zhou, 2015). For example, prior research has explicitly demonstrated that instructor selfdisclosure of their drinking behaviors on Facebook negatively affects perceived teacher credibility (Wang et al., 2015). Borzea and Goodboy (2016) recommend that instructors avoid disclosing their personal drinking behaviors in the classroom; however, both Study One and Nunziata (2007) found that students do experience their instructors disclosing personal drinking behaviors and was subsequently perceived it as inappropriate (negative) in both studies. Specifically, Hosek and Thompson (2009) found that instructor disclosing alcohol consumption has the potential to damage teacher credibility. Thus, the present study seeks to determine if there is a relationship between instructors disclosing their personal alcohol use behaviors and decreased instructor credibility.

In order to understand the perceived drinking norms of the participants and determine their perceived appropriateness of alcohol use on campus, the present research employed a measure of injunctive and descriptive norms. Furthermore, as a direct follow-up to Study One, the present study used the qualitative data about students' experience with instructors discussing alcohol in the classroom to specifically explore how these experiences affect student-teacher rapport, homophily, and perceived instructor credibility. Thus, four additional research questions were proposed:

$\mathrm{RQ}_{5}$ : How do participants perceive the appropriateness of alcohol use on campus?

$\mathrm{RQ}_{6}$ : Are there differences among contexts of an instructor discussing alcohol in the classroom in impact on rapport? 
$\mathrm{RQ}_{7}$ : Are there differences among contexts of an instructor discussing alcohol in the classroom in impact on student-teacher homophily?

$\mathrm{RQ}_{8}$ : Are there differences among contexts of an instructor discussing alcohol in the classroom in impact on instructor credibility?

\section{Quantitative Method}

\section{Participants}

Sampling. Participants for Study Two were sampled from a midsized public Midwestern university and were offered the opportunity to participate in the study via an online communication research portal. Additionally, a university-wide listserv was utilized to email students an invitation to take part in the study. Criterion sampling was utilized to ensure that participants were over the age of 18 and a current student at a college or university. Some participants, at the discretion of their specific instructor, received extra credit in their communication course for completing the survey. All respondents gave informed consent, were notified that they could stop the survey at any time, and were assured that their survey answers would remain anonymous.

Demographics. The mean of the 205 participants who completed the survey in full was 21.57 years of age $(S D=3.71)$. The sample was $73.8 \%$ female, $21 \%$ male, and less than $0.5 \%$ fluid or genderqueer, with $4.8 \%$ of participants choosing not to disclose their gender identity. Of those surveyed, $80.5 \%$ identified as White, $4.3 \%$ as African American, $3.3 \%$ as Hispanic/Latino(a), less than $1.0 \%$ as Asian or Pacific Islander, and less than $0.5 \%$ as Middle Eastern, with $10.5 \%$ choosing "other" or not disclosing their racial identity. The most frequent level of education achieved by participants was High School or GED equivalent at 51.9\%, 
followed by associate degree $(23.8 \%)$, bachelor degree $(15.7 \%)$, and master degree $(3.3 \%)$, with $5.3 \%$ of participants choosing not to disclose the highest level of education they completed.

\section{Research Design}

The present study was conducted using one independent variable with five levels. The independent variable and subsequent groups in this study were derived from the findings of the qualitative exploratory research on how college students have experienced instructors discussing alcohol in the classroom. The independent variable was how the instructor discussed alcohol in the classroom. This independent variable was broken down into five groups, all of which were themes found in the first (qualitative) study: (a) student past alcohol use, (b) student future alcohol use, (c) instructor advocating safe drinking behavior, (d) alcohol as part of the curriculum, and (e) instructor's personal drinking behaviors. Crucially, approximately 40 participants were assigned to each group of the independent variable in the present study in an effort to achieve the desired power level of .80 for detection of an effect of medium size at $p=$ .05 (Keppel, 1991).

Participants were randomly exposed to one of the five groups within the independent variable by reading vignettes containing quotes or paraphrased examples provided by the respondents in Study One on students' experiences with their instructors discussing alcohol in the classroom. These quotes or paraphrased examples were related to one of five contexts (student past alcohol use, student future alcohol use, instructor advocating safe drinking behavior, alcohol as part of the curriculum, and instructor's personal drinking behaviors) and the participants were asked to visualize a typical university instructor engaging in said behaviors. Due to context-specific nature of the independent variable, vignettes were selected as the most appropriate stimuli for the present study because, as Finch (1987) notes, 
Vignettes move further away again from a direct and abstracted approach and allow for features of the context to be specified so that the respondent is being invited to make normative statements about a set of social circumstances, rather than to express his or her 'beliefs' or 'values' in a vacuum. (pp. 105-106)

A manipulation check was conducted to ensure that participants perceived the five stimuli as an accurate reflection of the five groups within the independent variable. After completing the survey, participants were shown the stimuli and a list of the five contexts of instructors discussing alcohol; using Likert-type scales, they were asked to indicate how well each context described the vignette ( 1 = Doesn't Describe at All; 5 = Describes Very Well).

The dependent variables for this experiment were student descriptive and injunctive drinking norms (Crawford \& Novak, 2010), student-teacher rapport (Frisby \& Martin, 2010) and attitude homophily (L. L. McCroskey et al., 2006) as well as teacher credibility (J. C. McCroskey \& Teven, 1999). When asked how the instructor discussion of alcohol in the classroom affected their perception of the instructor, respondents in Study One appeared to indicate that the behavior affected aspects of the student-teacher relationship such as level of closeness and perception of teacher credibility. Thus, this quantitative follow-up experiment was conducted to elucidate the precise relationship between the way an instructor discusses alcohol in the classroom and student-teacher rapport, homophily, and perceived instructor credibility.

\section{Procedure}

After giving informed consent, participants completed a four-item measure for descriptive drinking norms (Cronbach's $\alpha=.72$ ) and a two-item measure for injunctive drinking norms $(r=.61, p<.001$; Crawford \& Novak, 2010). Following the researcher's instructions to compute the scale of descriptive drinking norms, the first three descriptive norms questions were 
standardized and then added together to form a composite measure. Furthermore, Crawford and Novak (2010) indicate that there is "some evidence that women respond to these kinds of questions using males as a point of reference" (p. 72). Therefore, all descriptive drinking norm questions included instructions to respond to the prompt as a typical student "who shares your gender identity" (see survey in Appendix C) thus mitigating Crawford and Novak's concerns. Participants were asked how many alcoholic drinks a student at their university who shared their gender identity consume per sitting and per week, as well as the number of times an average student is intoxicated during an average month. For the descriptive norms questions, an "alcohol drink" was conceptualized as one beer, glass of wine, or shot of spirits. An additional descriptive drinking norms question was included asking participants whether they thought students at their university drank more than students at other universities, which, according to Crawford and Novak, "reflect the extent to which students regard their institution as a 'party' school" (p. 73). To measure injunctive norms, the two-item Likert-type prompts $(1=$ Strongly Disagree $; 5=$ Strongly Agree) addressing participants' perception of the appropriateness of alcohol on campus were summed.

Participants were then randomly exposed to one of the five stimuli, which were actual quotes or paraphrased examples of instructors discussing alcohol in the classroom (see Appendix D); the stimuli represented the aforementioned five contexts of an instructor discussing alcohol. After reading the vignettes, participants took a questionnaire with slightly modified versions of Frisby and Martin's (2010) ten-item instructor-student rapport scale (Cronbach's $\alpha=.93$ ), L. L. McCroskey et al.'s (2006) 13-item attitude homophily scale (Cronbach's $\alpha=.92$ ), and McCroskey and Teven's (1999) 18-item source credibility scale (Cronbach's $\alpha=.94)$. The only modification made to the scales was changing the determiners in the prompts to more accurately 
suit this research design (e.g., "My instructor relates well to me" changed to "This instructor relates well to me").

\section{Results}

\section{Scale Reliability}

Reliability coefficients were calculated for all dependent variables in the present study. The pre-stimuli measures provided by Crawford and Novak (2010) had an alpha coefficient of .71 for descriptive drinking norms, indicating modest reliability (Lance, Butts, \& Michels, 2006). The two-item measure of injunctive norms were moderately correlated $(r=.58, p<.01$; Cohen, 1988). Frisby and Martin's (2010) measure of instructor-student rapport obtained a Cronbach's $\alpha$ $=.95$. L. L. McCroskey et al.'s (2006) measure of attitude homophily obtained a Cronbach's $\alpha=$ .95. McCroskey and Teven's (1999) source credibility scale is conceptualized with three dimensions, competence $(\alpha=.91)$, caring/goodwill $(\alpha=.90)$, and trustworthiness $(\alpha=.87)$. For the purposes of the multivariate analysis of variance, the present study collapsed these three dimensions into one measure of credibility, an option McCroskey and Teven offer; the reliability coefficient for the scale when scored as a single measure was $\alpha=.96$. All post-stimuli measures in the present study had alpha reliabilities over .80 , the recommended reliability coefficient for most widely used scales (Carmines \& Zeller, 1979; Lance et al., 2006), indicating sufficient internal reliability.

\section{Vignette Reliabilities}

A manipulation check was conducted in order to determine the reliability of the vignettes and ascertain if the five levels of the IV accurately represented the different contexts of an instructor discussing alcohol in the classroom. At the end of the survey, participants were shown the vignette again and asked to indicate on a five-point Likert-type scale how well each context 
describes the vignette $(1=$ Does Not Describe All; $5=$ Describes Very Well $)$; essentially creating single-item dependent variables to measure if the stimuli accurately reflected the context it was attempting to portray. A one-way multivariate analysis of variance (MANOVA) was conducted with the vignette and five levels as the independent variable and the five manipulation check questions as the dependent variables. The Box's M value of 158.293 was statistically significant, $F(60,76392.48)=2.49, p<.001$, which indicated that the dependent variable variancecovariance matrices were not equal across the levels of the independent variable, violating the assumption of homogeneity (Meyers, Gamst, \& Guarino, 2017). Following Meyers et al.'s (2017) guidelines, Pillai's V was used to evaluate the multivariate effects, as it is "less affected by violations of the variance-covariance homogeneity assumption" (p. 771).

The omnibus MANOVA detected a statistically significant difference, $F(5,20)=9.315, p$ $<.001$, Pillai's $\mathrm{V}=.771$, multivariate $\eta^{2}=.19$ among the five manipulation check questions; additionally, Bartlett's Test of Sphericity (approximate $\chi^{2}=412.22, d f=5, p<.001$ ) indicated sufficient correlation between these dependent variables (Meyers et al., 2017). Prior to follow-up ANOVAs, Levene's test was used to test the homogeneity of variance assumption; with the exception of the student past alcohol use manipulation check, Levene's test indicated that all other dependent variables had homogeneity of variance $(p>.05)$.

Follow-up ANOVAs indicated a statistically significant difference for three of the manipulation checks across the five levels of the independent variable: Advocating for Safe Drinking Behavior, $F(4,196)=32.53, p<.001, \eta^{2}=.40$; Personal Alcohol Use Behaviors, $F(4$, 196) $=14.33, p<.001, \eta^{2}=.23$; Part of the Curriculum: $F(4,196)=4.68, p=.001, \eta^{2}=.09$. Two of follow-up ANOVAs did not indicate a statically significant difference: Student Future Alcohol Use, $F(4,196)=1.50, p=.205, \eta^{2}=.03$; Student Past Alcohol Use: $F(4,196)=2.17, p=.073$, 
$\eta^{2}=.04$. Since the homogeneity of variance assumption was violated, Tamhane's T2 post hoc tests were conducted (Meyers et al., 2017) to determine if there was a statistically significant difference between the five levels of the independent variable for each manipulation check (see Table 5). These findings indicate that the Advocating for Safe Drinking Behavior, Personal Alcohol Use Behavior, and Part of the Curriculum vignettes were distinct representations of the phenomenon they were attempting to encapsulate. However, the Student Future Alcohol Use and Student Past Alcohol Use manipulation check questions were perhaps not discrete enough from the other contexts; for example, participants may have found that the vignette Advocating for Safe Drinking Behavior also described Student Future Alcohol Use, as encouraging safe alcohol use is inherently in reference to students' future alcohol consumption behaviors. 
Table 5

Manipulation Check with Tamhane's T2 Post-Hoc Test Results and Descriptive Statistics

\begin{tabular}{|c|c|c|c|}
\hline $\begin{array}{l}\text { Manipulation Check Question } \\
\text { Vignette }\end{array}$ & $M$ & $S D$ & $N$ \\
\hline Advocating for Safe Drinking Behavior & 2.71 & 1.37 & 201 \\
\hline Advocating for Safe Drinking Behavior ${ }^{\text {bcde }}$ & 4.32 & 0.99 & 41 \\
\hline Personal Alcohol Use Behaviors ${ }^{\text {ace }}$ & 1.79 & 1.07 & 38 \\
\hline Part of the Curriculum ${ }^{\mathrm{ab}}$ & 2.61 & 1.07 & 41 \\
\hline Student Future Alcohol Use ${ }^{a}$ & 2.21 & 1.15 & 39 \\
\hline Student Past Alcohol Use ${ }^{\mathrm{ab}}$ & 2.52 & 1.09 & 42 \\
\hline Personal Alcohol Use Behaviors & 2.84 & 1.47 & 201 \\
\hline Advocating for Safe Drinking Behavior ${ }^{b}$ & 2.54 & 1.40 & 41 \\
\hline Personal Alcohol Use Behaviors ${ }^{\text {acde }}$ & 4.26 & 1.08 & 38 \\
\hline Part of the Curriculum ${ }^{\mathrm{b}}$ & 2.34 & 1.32 & 41 \\
\hline Student Future Alcohol Use ${ }^{b}$ & 2.69 & 1.44 & 39 \\
\hline Student Past Alcohol Use ${ }^{\mathrm{b}}$ & 2.45 & 1.27 & 42 \\
\hline Part of the Curriculum & 2.60 & 1.34 & 201 \\
\hline Advocating for Safe Drinking Behavior & 2.54 & 1.42 & 41 \\
\hline Personal Alcohol Use Behaviors & 2.61 & 1.20 & 38 \\
\hline Part of the Curriculum ${ }^{\mathrm{e}}$ & 3.22 & 1.26 & 41 \\
\hline Student Future Alcohol Use & 2.64 & 1.35 & 39 \\
\hline Student Past Alcohol Use ${ }^{c}$ & 2.00 & 1.21 & 42 \\
\hline Student Future Alcohol Use & 4.00 & 0.95 & 201 \\
\hline Advocating for Safe Drinking Behavior & 4.15 & 1.01 & 41 \\
\hline Personal Alcohol Use Behaviors & 3.68 & 1.07 & 38 \\
\hline Part of the Curriculum & 3.98 & 0.76 & 41 \\
\hline Student Future Alcohol Use & 4.05 & 1.05 & 39 \\
\hline Student Past Alcohol Use & 4.12 & 0.83 & 42 \\
\hline Student Past Alcohol Use & 3.87 & 1.03 & 201 \\
\hline Advocating for Safe Drinking Behavior & 3.88 & 1.19 & 41 \\
\hline Personal Alcohol Use Behaviors & 3.55 & 1.03 & 38 \\
\hline Part of the Curriculum & 3.88 & 0.95 & 41 \\
\hline Student Future Alcohol Use & 3.79 & 1.11 & 39 \\
\hline Student Past Alcohol Use & 4.21 & 0.72 & 42 \\
\hline
\end{tabular}

Note. The letters (a, b, c, etc.) represent each context of an instructor discussing alcohol. Letters next to a level of the IV indicate that the Tamhane's T2 post hoc test found a statistically significant difference $(p<.05)$ between the contexts within that manipulation check.

${ }^{\mathrm{a}}$ Advocating for Safe Drinking Behavior, ${ }^{\mathrm{b}}$ Personal Alcohol Use Behaviors, ${ }^{\mathrm{c}}$ Part of Curriculum, ${ }^{\mathrm{d}}$ Student Future Alcohol Use, ${ }^{\mathrm{e}}$ Student Past Alcohol Use. 


\section{Descriptive and Injunctive Drinking Norms}

Descriptive statistics show that the mean number of alcoholic drinks reported was 3.91 per sitting $(S D=2.73, N=201)$ and 10.78 drinks per week $(S D=6.73, N=199)$; the mean number of times intoxicated during an average month was $7.89(S D=8.37, N=200$; see Table 6). However, the question asking participants about the number of times a typical student is intoxicated during an average month had significant variation in the data, with a standard deviation higher than the mean itself; responses to this question ranged from 0 to 60 with a majority of participants citing between zero and five times intoxicated during an average month ( $n=101,51 \%$ of total responses). The mean response to the additional descriptive norms prompt regarding whether the students perceive their school to be a "party" school was $2.85(S D=.90, N$ $=210)$ on a five-point Likert-type scale. A majority of respondents $(n=75,36 \%$ of total responses; see Figure 2 in Appendix B) indicated that they neither agreed nor disagreed with this supplementary descriptive norm measure ("Students here at drink more than students at other colleges and universities"). However, more participants disagreed or strongly disagreed ( $n$ $=82,39 \%$ of total responses $)$ with this statement than agreed or strongly agreed $(n=53,25 \%$ of total responses).

Injunctive norms were also measured on a five-point Likert-type scale. The mean response to the prompt "most students think it's okay to get drunk at parties" was $4.15(S D=.80$, $N=209$ ). The mean response to the prompt "drinking is considered to be a desirable activity on this campus" was $4.00(S D=.82, N=209)$. The composite measure of injunctive norms, created by adding the two aforementioned questions together, had a mean of $8.15(S D=1.44, N=209)$.

Research question five asked how participants perceive the appropriateness of alcohol use on campus. The measure of injunctive drinking norms, a measure of perceived 
appropriateness of alcohol use on campus (Crawford \& Novak, 2010), showed that participants tended to agree that drinking alcohol was an appropriate behavior on campus. A large majority, approximately $86 \%(n=180)$, either agreed or strongly agree that most students at their university get drunk at parties (see Figure 3 in Appendix B). Additionally, about 82\% of respondents $(n=172)$ either agreed or strongly agreed that drinking alcohol is a desirable activity on campus (see Figure 4 in Appendix B).

Table 6

Drinking Norms Descriptive Statistics

Question

How many alcoholic drinks (beer, wine, shot of spirits, etc.) does a typical student at Illinois State University who shares your gender identity consume per sitting? ${ }^{\mathrm{a}}$

How many alcoholic drinks (beer, wine, shot of spirits, etc.) does a typical student at Illinois State University who shares your gender identity consume per week?

How many times is a typical student at Illinois State University who shares your gender identity intoxicated during an average month?

Students here at Illinois State University drink more than students at other colleges and universities. $(1=\text { Strongly Disagree } ; 5=\text { Strongly Agree })^{\mathrm{a}}$

Most Illinois State University students think it's okay to get drunk at parties.

$(1=\text { Strongly Disagree } ; 5=\text { Strongly Agree })^{\mathrm{b}}$

Drinking alcohol is considered to be a desirable activity on this campus.

$(1=\text { Strongly Disagree } ; 5=\text { Strongly Agree })^{\mathrm{b}}$
0.80

209

N

201

199

4.00

0.82

209

Note. ${ }^{a}$ Descriptive Drinking Norms, ${ }^{b}$ Injunctive Drinking Norms 


\section{Correlation between Dependent Variables}

Prior to conducting the multivariate analysis, a series of Pearson product moment correlations were performed between the three post-stimuli dependent variables in order to test the fundamental assumption that the dependent variables are moderately correlated and justify the use of a MANOVA (Meyers et al., 2017). All dependent variables were moderately correlated which suggested the appropriateness of a MANOVA (Meyers et al., 2017; see Table 7).

\section{Multivariate Analysis}

A one-way MANOVA was conducted to determine if there was a statistically significant difference between the five different contexts of an instructor discussing alcohol in the university classroom (advocating for safe drinking behavior, personal alcohol use behaviors, part of the curriculum, student future alcohol use and student past alcohol use) and the measures for rapport, homophily, and credibility. The omnibus MANOVA detected a statistically significant difference, $F(12,513.57)=8.79, p<.001$, Wilks' $\lambda=.61$, multivariate $\eta^{2}=.13$. Bartlett's Test of Sphericity (approximate $\chi^{2}=412.22, d f=5, p<.001$ ) affirmed the sufficient correlation between the dependent variables (Meyers et al., 2017) detected in the prior Pearson product moment correlation tests. Following Huberty and Petoskey's (2000) guidelines, the Box's M value of 30.67 was not statistically significant, $F(24,104970.11)=1.234, p=.197$, which indicated that the covariance matrices among the groups were assumed to be equal.

The homogeneity of variance assumption was tested and met for all three measures prior to univariate follow-up ANOVAs to determine how the three dependent variables differed on the independent variable. The Levene's tests for rapport, $F(4,196)=1.01, p=.40$; homophily, $F(4$, 
$196)=2.32, p=.06 ;$ and credibility $F(4,196)=1.68, p=.16$, all indicated no statistically

significant differences in variance among the test groups on the dependent variables.

Table 7

Sample Size, Means, Standard Deviations, and Pearson Correlations of DVs

\begin{tabular}{lcccccc}
\hline & $N$ & $M$ & $S D$ & 1 & 2 & 3 \\
\hline 1 Rapport & 205 & 23.93 & 7.51 & 1.0 & .73 & .69 \\
2 Homophily & 204 & 38.12 & 10.11 & .73 & 1.0 & .69 \\
3 Credibility & 201 & 83.87 & 21.48 & .69 & .69 & 1.0 \\
\hline
\end{tabular}

Note. All correlations are statistically significant $(p<.001)$.

Research question six asked if there are differences among the contexts an instructor discusses alcohol in the classroom and student-teacher rapport. A follow-up ANOVA detected statistically significant differences between the context alcohol was discussed and rapport, $F(4$, $196)=10.28, p<.001, \eta^{2}=.17$. A series of Tukey HSD post-hoc tests were then conducted to determine where statistically significant differences existed among the five levels of the independent variable for student-teacher rapport (see Table 8 for differences).

Research question seven asked if there are differences among the contexts an instructor discusses alcohol in the classroom and student-teacher homophily. A follow-up ANOVA detected statistically significant differences between the context alcohol was discussed and homophily, $F(4,196)=15.56, p<.001, \eta^{2}=.24$. A series of Tukey HSD post-hoc tests were then conducted to determine where statistically significant differences occurred among the five test groups of the independent variable for student-teacher homophily (see Table 8 for differences). 
Research question eight asked if there are differences among the contexts in which an instructor discusses alcohol in the classroom and instructor credibility. A follow-up ANOVA detected statistically significant differences among the contexts in which alcohol was discussed and credibility $F(4,196), p<.001, \eta^{2}=.34$. A series of Tukey HSD post-hoc tests were then conducted to determine where statistically significant differences occurred among the five levels of the independent variable for instructor credibility (see Table 8 for differences). As previously mentioned, caring is perhaps the most important construct when measuring instructor credibility (Finn et al., 2009). Based on the findings of Study One, the present study sought to specifically investigate how an instructor discussing alcohol affects McCroskey and Teven's (1999) measure of caring as a sub-scale of credibility. Therefore, a final follow-up ANOVA was conducted using only the caring measure as a dependent variable; however, the Levene's test indicated variance heterogeneity, $F(4,196)=2.47, p=.046$. Following Lix, Keselman, and Keselman's (1996) guidelines, a Welch (1951) test, which does not have an assumption of homogeneity, was conducted instead; the Welch ANOVA indicated a statistically significant difference between the five groups on the caring measure, $F(4,97)=27.08, p<.001$. A series of Games-Howell posthoc tests, which do not rely on equal sample size or variance homogeneity (Hsiung \& Olejnik, 1994), were then conducted to determine if there is a statistically significant difference between the five levels of the independent variable for the caring subscale (see Table 8 for differences). 
Table 8

MANOVA Post-Hoc Test Results and Descriptive Statistics

\begin{tabular}{|c|c|c|c|}
\hline $\begin{array}{c}\text { Dependent Variable } \\
\text { Vignette }\end{array}$ & $M$ & $S D$ & $N$ \\
\hline Rapport & 28.93 & 7.51 & 205 \\
\hline $\begin{array}{l}\text { Advocating for Safe Drinking Behavior }{ }^{\text {bce }} \\
\text { Personal Alcohol Use Behaviors } \\
\text { Parte } \\
\text { Part the Curriculum }{ }^{a b} \\
\text { Student Future Alcohol Use } \\
\text { Student Past Alcohol Use }\end{array}$ & $\begin{array}{l}33.66 \\
23.71 \\
29.24 \\
29.41 \\
28.14\end{array}$ & $\begin{array}{l}7.63 \\
7.18 \\
5.63 \\
6.61 \\
7.53\end{array}$ & $\begin{array}{l}41 \\
38 \\
41 \\
39 \\
42\end{array}$ \\
\hline Homophily & 38.11 & 10.11 & 204 \\
\hline $\begin{array}{l}\text { Advocating for Safe Drinking Behavior }{ }^{\text {bcde }} \\
\text { Personal Alcohol Use Behaviors }{ }^{\text {ace }} \\
\text { Part of the Curriculum } \\
\text { Student Future Alcohol Use } \\
\text { Student Past Alcohol Use } \\
\text { Seb }^{\mathrm{a}}\end{array}$ & $\begin{array}{l}47.02 \\
31.68 \\
37.68 \\
36.23 \\
37.38\end{array}$ & $\begin{array}{c}9.86 \\
10.46 \\
6.56 \\
8.38 \\
9.11\end{array}$ & $\begin{array}{l}41 \\
38 \\
41 \\
39 \\
42\end{array}$ \\
\hline Credibility & 83.87 & 21.48 & 201 \\
\hline $\begin{array}{l}\text { Advocating for Safe Drinking Behavior }{ }^{\text {bcde }} \\
\text { Personal Alcohol Use Behaviors }{ }^{\text {acde }} \\
\text { Part of the Curriculum }{ }^{\text {ab }} \\
\text { Student Future Alcohol Use } \\
\text { Student Past Alcohol Use } \\
\text { ab }\end{array}$ & $\begin{array}{l}106.37 \\
67.68 \\
82.83 \\
80.79 \\
80.40\end{array}$ & $\begin{array}{l}17.80 \\
18.87 \\
16.22 \\
14.93 \\
19.62\end{array}$ & $\begin{array}{l}41 \\
38 \\
41 \\
39 \\
42\end{array}$ \\
\hline Caring (credibility subscale) & 27.14 & 7.75 & 201 \\
\hline $\begin{array}{l}\text { Advocating for Safe Drinking Behavior }{ }^{\text {bcde }} \\
\text { Personal Alcohol Use Behaviors } \\
\text { Part of Curriculum }^{\text {ab }} \\
\text { Student Future Alcohol Use }^{\text {ab }} \\
\text { Student Past Alcohol Use }^{\mathrm{a}}\end{array}$ & $\begin{array}{l}35.44 \\
21.66 \\
25.88 \\
27.67 \\
24.14\end{array}$ & $\begin{array}{l}6.13 \\
6.25 \\
5.77 \\
5.24 \\
7.75\end{array}$ & $\begin{array}{l}41 \\
38 \\
41 \\
39 \\
42\end{array}$ \\
\hline
\end{tabular}

Note. The letters (a, b, c, etc.) represent each context of an instructor discussing alcohol. Letters next to a level of the IV indicate that the post hoc test (Tukey's HSD for rapport, homophily, and credibility, and Games-Howell for the caring subscale) found a statistically significant difference $(p<.05)$ between the contexts within that dependent variable. ${ }^{a}$ Advocating for Safe Drinking Behavior, ${ }^{\mathrm{b}}$ Personal Alcohol Use Behaviors, ${ }^{\mathrm{c}}$ Part of Curriculum, ${ }^{\mathrm{d}}$ Student Future Alcohol Use, e Student Past Alcohol Use. 


\section{Quantitative Discussion}

As a direct follow-up to Study One, Study Two focused on how the context an instructor discusses alcohol in the classroom affects the students' relationship with their instructor, perceived similarity, as well as their perception of the instructor's credibility. The present study found that the way an instructor mentions alcohol in the class does indeed impact measures of rapport, homophily, and instructor credibility.

\section{Descriptive and Injunctive Norms}

The present study employed measures of student alcohol norms in order to establish a baseline understanding of participants' perception of how much and how frequently their peers consume alcohol (descriptive norms), and the moral rules that govern perceived approval of peer alcohol use (injunctive norms; Borsari \& Carey, 2001, 2003; Crawford \& Novak, 2010). The data indicated that participants perceived that their peers, on average, become intoxicated approximately eight times every month, drinking an average of nearly eleven drinks per week, and about four drinks per sitting; this demonstrates that alcohol is indeed perceived as a common peer activity on campus. Additionally, the injunctive norms measure indicated that a majority of participants perceived alcohol as an appropriate activity at their university.

\section{Rapport}

The present study examined how the context an instructor discusses alcohol in the classroom affects student-teacher rapport. Rapport was conceptualized as a prosocial bond of mutual trust and a personal connection between a student and their instructor (Frisby \& Housley Gaffney, 2015). The data indicated that the vignette where instructors advocated for safe drinking behavior was rated significantly higher rated in producing student-teacher rapport than all other contexts except student future alcohol use. The instructor discussing their personal 
drinking behaviors resulted in significantly lower scores than any other scenario on the rapport measure. The vignettes where instructors discussed drinking as part of the curriculum, in terms of student future alcohol use, and student past alcohol use did not differ from one another in their effect on student rapport; however, all three scored significantly higher on rapport than discussion of personal drinking behavior and significantly lower than advocating for safe drinking behavior.

\section{Homophily}

The present study also examined how instructors discussing alcohol in the classroom affected homophily, or perceived similarity (J. C. McCroskey et al., 1975). The data indicated that the vignette where instructors advocated for safe drinking behavior was rated significantly higher in homophily than all other vignettes on the homophily measure. An instructor discussing their personal alcohol use behaviors resulted in significantly lower scores than all other scenarios on the homophily measure except the student future alcohol use vignette. The vignettes where instructors discussed drinking as part of the curriculum, in terms of student future alcohol use, and student past alcohol use did not differ from one another in their effect on student homophily; however, the discussing alcohol as part of the curriculum and student past alcohol use vignettes scored significantly higher on homophily than discussion of personal drinking behavior and significantly lower than advocating for safe drinking behavior context. These findings have significant real-world applications, as university instructors can tailor the way they mention alcohol in the classroom to maximize homophily, which in turn can increase verbal immediacy (Powell et al., 2001). 


\section{Credibility}

The data indicated that the vignette where instructors advocated for safe drinking behavior was rated significantly higher in producing credibility than all other vignettes. The instructor discussing their personal drinking behaviors resulted in significantly lower scores than any other scenario on the credibility measure. The stimuli where instructors discussed drinking as part of the curriculum, in terms of student future alcohol use, and student past alcohol use did not differ from one another in their effect on credibility; however, all three scored significantly higher on credibility than discussion of personal drinking behavior and significantly lower than advocating for safe drinking behavior. An instructor discussing their personal drinking behaviors having a negative impact on credibility is unsurprising, as past research has shown that this type of self-disclosure can potentially have a negative impact on the perceived credibility of an instructor (Hosek \& Thompson, 2009; Wang et al., 2015).

The caring subscale yielded comparable results. The data indicated that the vignette where instructors advocated for safe drinking behavior was rated significantly higher in the caring dimension of credibility compared to all other contexts. The vignette where the instructor discussed their personal drinking behaviors resulted in significantly lower scores compared to all other scenarios except student past alcohol use on the caring dimension of credibility measure. The vignettes where instructors discussed drinking as part of the curriculum, in terms of student future alcohol use, and student past alcohol use did not differ from one another in their effect on the caring dimension of credibility; however, all three scored significantly lower than advocating for safe drinking behavior. Finally, discussing alcohol as part of the curriculum and student future alcohol use scored significantly higher on the caring dimension of credibility than discussion of personal drinking behavior. These results are noteworthy, as research has shown 
that instructors demonstrating the caring dimension of credibility, in this case promoting safe alcohol consumption behaviors, can affect cognitive and affective learning (Teven \& McCroskey, 1997). Additionally, previous communication studies have also demonstrated that an instructor showing that they care for their students not only increases their credibility (McCroskey \& Teven, 1999; Teven \& Hanson, 2004), it can promote student-teacher rapport as well (Benson et al., 2005; Murphy \& Rodríguez-Manzanares, 2012).

\section{Strengths and Limitations}

Study Two had several strengths, the primary one being that the vignettes were constructed from actual quoted and paraphrased statements provided by students in Study One who experienced their instructor discussing alcohol in the classroom. By utilizing actual quotes, the vignettes were as close as possible to mimicking actual instructor dialog in the classroom. Additionally, participants were randomly assigned to read the different vignettes, with each participant having an equal chance to be exposed to each of the five stimuli; this maintained the underlying principle of individual equivalency, a necessity for experimental research (Keyton, 2010).

One of the limitations of the present study was that the participants surveyed were relatively homogeneous; approximately eighty percent of the total sample were White and over $70 \%$ of participants surveyed were women. Another limitation was that the manipulation check indicated that there was not a statistically significant difference between several of the vignettes; the lack of distinction between the stimuli is likely due to two factors. First, the manipulation check consisted of only five questions asking participants to indicate how well each context of instructor discussing alcohol in the classroom (advocating for safe drinking behavior, personal alcohol use behaviors, etc.) described the vignette they were viewing. If the present study is to be 
replicated, several more questions should be constructed in order to determine the validity of the stimuli. Additionally, there was likely some overlap between categories. As previously mentioned, if an instructor is advocating for safe drinking behavior she or he is also inextricably discussing student drinking alcohol in the future. This overlap, in conjunction with the limited questionnaire associated with the manipulation check, may explain why the data indicated that the individual vignettes were not all perceived to be distinct from one another.

\section{Conclusion}

Study Two found that an instructor self-disclosing their own drinking behaviors had the most negative impact on the rapport, homophily, and credibility measures; in fact, the mean scores for all three measures were the lowest for this level of the independent variable.

Conversely, instructors advocating for safe student alcohol consumption behavior were considered to be more homophilous, credible, and have better student-teacher rapport. While there may be unexplored contexts where it is appropriate for an instructor to mention alcohol, the findings of the present study are clear; if instructors mention alcohol in the classroom, the most appropriate context demonstrated by empirical research thus far is to implore their students to imbibe safely and responsibly. 


\section{CHAPTER V: GENERAL DISCUSSION \\ Summary of Findings}

\section{Qualitative Study (Study One)}

Study One found that students have experienced their instructors discussing alcohol in university classrooms. Specifically, thematic coding revealed that instructors mention alcohol in the following contexts: student past/future alcohol use, advocating for safe student alcohol use, joking about student alcohol use, alcohol in the curriculum, and the instructor discussing their personal alcohol use behaviors. Study One also found that a majority of participants perceived the mention of alcohol to be appropriate. The perceived appropriateness of the instructor discussing alcohol was based on whether it was relevant to students or relevant to class, with participants reporting irrelevant mentions of alcohol as inappropriate. A majority of participants indicated that their instructor mentioning alcohol did not change the way they perceived their teacher; however, of those who did, nearly three-quarters said it was a positive change. Finally, Study One investigated the relationship between appropriateness and change in perception. The majority of participants who reported the mention of alcohol as appropriate had a positive change in their perception of the instructor, while a majority of those who thought the behavior was inappropriate had a negative change in their perception.

\section{Quantitative Study (Study Two)}

Since Study One found that students recall their instructors discussing alcohol in the classroom in various contexts, Study Two examined how this behavior affected a student's perception of the teacher. Additionally, the follow-up study quantitatively measured participants' perception of peer alcohol consumption behaviors and the perceived appropriateness of alcohol on campus. Study Two found that participants do indeed perceive that their peers are consuming 
alcohol and that it is an appropriate activity on campus. However, the data did not indicate that students perceived their school to be a "party school." A majority of respondents were neutral in response to the supplementary descriptive drinking norms prompt and those who did have a sentiment primarily disagreed that students at their university drink more than students at other universities. The findings regarding student drinking norms are important to determine if alcohol is part of the participants' lives; if students did not perceive alcohol use as a normative behavior, it may affect how a teacher discussing alcohol use in the classroom influences student perceptions of their instructor.

Study Two also found that the context an instructor mentions alcohol in the classroom can indeed affect a student's perception of their instructor. Specifically, hypothetical instructors who advocated for safe drinking behavior were rated significantly higher on rapport, homophily, and credibility. Conversely, participants rated hypothetical instructors who discussed their personal alcohol use as being less homophilous and credible, as well as having less studentteacher rapport. Finally, instructors discussing alcohol as part of the curriculum, student past alcohol use, and student future use generally did not affect these three measures significantly compared to the other contexts.

\section{Synthesis of Study One and Study Two Findings}

Study One found that students experienced their university instructor discussing alcohol in multiple contexts, and these mentions of alcohol in the classroom had the potential to affect a student's perception of the instructor in positive and negative ways. The findings of Study Two demonstrate that the context alcohol is mentioned in the classroom can have direct effects on the perceived rapport, homophily, and credibility of an instructor. However, an instructor 
mentioning alcohol as part of the curriculum, discussing past student alcohol use, and student future use did not appear to differ, overall, on these three measures.

Study Two did indicate, though, that if an instructor is to mention alcohol in the classroom, they should advocate for their students to drink alcohol safely. Instructors should avoid mentioning their personal alcohol use behaviors in front of students, as this context yielded drastically lower scores on rapport, homophily, and credibility. These results are perhaps not surprising given the findings of Study One. In Study One, participants indicated that mentions of alcohol that were irrelevant to either the course material or the students themselves are inappropriate. An instructor discussing their personal drinking behavior is irrelevant to the course and students, so the mention is likely perceived as inappropriate in the classroom, which results in a negative effect on perception overall, and consequently resulted in lower scores on the three dependent variables in Study Two. Conversely, an instructor advocating for safe drinking behavior is relevant to students; thus, the students perceive the behavior as appropriate, resulting in a positive change in perception overall, and the instructor is rated higher on the rapport, homophily, and credibility measures accordingly.

\section{Future Research}

Studies I and II established that, at least at the university sampled, participants perceived drinking alcohol as an acceptable behavior on campus. Since the study was conducted at a public university, future research should examine whether instructors discuss alcohol in other higher education institutions (private, community college, religious, trade schools, etc.). If the phenomenon exists at these other institutions, researchers could then see if the findings of the present study remain true in the different educational contexts. 
Additionally, future studies could organize focus groups to discuss with students both their experiences with instructors discussing alcohol in the classroom and the impact it had on their perception of the teacher. These focus groups would be a valuable method of collecting follow-up data to help explain the qualitative and quantitative findings of the present thesis (Morgan, 1997). As Morgan states, "Too often, the tendency is to throw every possible variable in the analysis and then retreat to armchair speculation about what might have created the results" (p. 27). Thus, subsequent focus groups could help elucidate the findings of the present study using participants own words instead of conclusions drawn by the researcher.

Finally, future researchers exploring this phenomenon should explicitly investigate whether the discussion of alcohol by an instructor in the classroom perpetuates the norm of alcohol abuse in higher education. Specifically, future studies should see if instructors who engage in this behavior perpetuate descriptive or injunctive drinking norms on their campus. Finally, future research should investigate the impact of instructor discussion of alcohol in the classroom on students who abstain from drinking. Multiple respondents in Study One reported that the discussion of alcohol was inappropriate and negatively affected their perception of the instructor because they did not drink and did not appreciate having their instructor presume that they did.

\section{Conclusion}

The present thesis found that instructors do discuss alcohol in the classroom, and they do so in a variety of different contexts. Students generally perceived the mentions of alcohol to be appropriate, resulting in a positive change in their perception of the instructor; appropriateness of the behavior appears to be determined based on perceived relevance to the course and perceived relevance to the students. The findings of Studies I and II indicate that there are contexts 
instructors should avoid, contexts which instructors can use to potentially increase the rapport they have with students, as well as perceived homophily and perceived credibility, and contexts that are innocuous. Specifically, instructors should advocate for their students to imbibe safely and avoid disclosing their personal drinking behaviors; however, discussing student past alcohol use, student future alcohol use, and mentioning alcohol as part of the curriculum are comparatively inconsequential. The present thesis serves as foundational research on instructors discussing alcohol in the university classroom and hopefully inspires future communication scholars to research this under-studied phenomenon that is clearly present in higher education. 


\section{REFERENCES}

American heritage dictionary (2nd ed.). (1991). Boston, MA: Houghton Mifflin.

Andersen, J. F. (1979). Teacher immediacy as a predictor of teaching effectiveness. In D.

Nimmo (Ed.), Communication Yearbook 3 (pp. 543-559). New Brunswick, NJ:

Transaction. doi:10.1080/23808985.1979.11923782

Astin, A.W. (1993). What matters in college? Four critical years revisited. San Francisco, CA: Jossey-Bass.

Baer, J. S., \& Carney, M. M. (1993). Biases in the perceptions of the consequences of alcohol use among college students. Journal of Studies on Alcohol, 54(1), 54-60. doi:10.15288/jsa.1993.54.54

Banas, J. A., Dunbar, N., Rodriguez, D., \& Liu, S. J. (2011). A review of humor in educational settings: Four decades of research. Communication Education, 60(1), 115-144. doi:10.1080/03634523.2010.496867

Beatty, M. J., \& Zahn, C. J. (1990). Are student ratings of communication instructors due to “easy" grading practices?: An analysis of teacher credibility and student-reported performance levels. Communication Education, 39, 275-282. doi:10.1080/03634529009378809

Benson, A. T., Cohen L. A., \& Buskist, W. (2005). Rapport: Its relation to student attitudes and behaviors toward teachers and classes. Teaching of Psychology, 32, 237-239. doi:10.1207/s15328023top3204_8

Berkowitz, A. D. (2005). An overview of the social norms approach. In L. C. Lederman \& L. P. Stewart (Eds.), Changing the culture of college drinking: A socially situated health communication campaign (pp. 187-208). Cresskill, NJ: Hampton Press. 
Berkowitz, A. D., \& Perkins, H. W. (1986). Problem drinking among college students: A review of recent research. Journal of American College Health, 35, 21-28.

Borsari, B., \& Carey, K. B. (2001). Peer influences on college drinking: A review of the research. Journal of Substance Abuse, 13(4), 391-424. doi:10.1016/s08993289(01)00098-0

Borsari, B., \& Carey, K. B. (2003). Descriptive and injunctive norms in college drinking: A meta-analytic integration. Journal of Studies on Alcohol, 64, 331-341. doi:10.15288/jsa.2003.64.331

Borzea, D., \& Goodboy, A. K. (2016). When instructors self-disclose but misbehave: Conditional effects on student engagement and interest. Communication Studies, 67, 548566. doi:10.1080/10510974.2016.1212912

Carmines, E. G., \& Zeller, R. A. (1979). Reliability and validity assessment. Newbury Park, CA: Sage.

Cayanus, J. L., \& Martin, M. M. (2008). Teacher self-disclosure: Amount, relevance, and negativity. Communication Quarterly, 56, 325-341. doi:10.1080/01463370802241492

Chory, R. M. (2007). Enhancing student perceptions of fairness: The relationship between instructor credibility and classroom justice. Communication Education, 56, 89-105. doi:10.1080/03634520600994300

Cohen, J. (1988). Statistical power analysis for the behavioral sciences (2nd ed.). Hillsdale, NJ: Lawrence Erlbaum Associates. 
Crawford, L. A., \& Novak, K. B. (2010). Beliefs about alcohol and the college experience as moderators of the effects of perceived drinking norms on student alcohol use. Journal of Alcohol and Drug Education, 54(3), 69-86. Retrieved from https://search.proquest.com/docview/820916176

Edwards, A., \& Edwards, C. (2001). The impact of instructor verbal and nonverbal immediacy on student perceptions of attractiveness and homophily. Journal on Excellence in College Teaching, 12(2), 5-17. Retrieved from http://celt.miamioh.edu/ject/issue.php?v=12\&n=2

Freese, J. H. (1926). Aristotle: The art of rhetoric. New York, NY: G. P. Putnam's Sons.

Finn, A. N., Schrodt, P., Witt, P. L., Elledge, N., Jernberg, K. A., \& Larson, L. M. (2009). A meta-analytical review of teacher credibility and its associations with teacher behaviors and student outcomes. Communication Education, 58, 516-537.

doi:10.1080/03634520903131154

Finch, J. (1987) Research note: The vignette technique in survey research. Sociology, 21, 105114. doi:10.1177/0038038587021001008

Frisby, B. N., \& Housley Gaffney, A. L. (2015). Understanding the role of instructor rapport in the college classroom. Communication Research Reports, 32(4), 340-346. doi:10.1080/08824096.2015.1089847

Frisby, B. N., \& Martin, M. M. (2010). Instructor-student and student-student rapport in the classroom. Communication Education, 59, 146-164. doi:10.1080=03634520903564362

Frisby, B. N., \& Myers, S. A. (2008). The relationships among perceived instructor rapport, student participation, and student learning outcomes. Texas Speech Communication Journal, 33, 27-34. Retrieved from http://www.etsca.com/journal.asp 
Frymier, A. B., \& Thompson, C. A. (1992). Perceived teacher affinity-seeking in relation to perceived teacher credibility. Communication Education, 41, 388-399. doi:10.1080/03634529209378900

Frymier, A. B., Wanzer, M. B., \& Wojtaszczyk, A. M. (2008). Assessing students' perceptions of inappropriate and appropriate teacher humor. Communication Education, 57(2), 266288. Retrieved from https://files.eric.ed.gov/fulltext/ED499080.pdf

Gorham, J. (1988). The relationship between verbal teacher immediacy behaviors and student learning. Communication Education, 37, 40-53. doi:10.1080/03634528809378702

Grantiz, N. A., Koernig, S. K., \& Harich, K. R. (2008). Now it's personal: Antecedents and outcomes of rapport between business faculty and their students. Journal of Marketing Education, 31, 52-65. doi:10.1177/0273475308326408

Gremler, D. D., \& Gwinner, K. P. (2000). Customer-employee rapport in service relationships. Journal of Service Research, 3, 82-104. doi:10.1177/109467050031006

Hansen, W. B. (1997). A social ecology theory of alcohol and drug use prevention among college and university students. In U.S. Department of Education (Ed.), Designing alcohol and other drug prevention programs in higher education: Bringing theory into practice (pp. 155-176). Newton, MA: Educational Development Center.

Heyne, R. M. (1984). An Assessment of The University of Cincinnati Faculty Perceptions and Knowledge Concerning Alcohol Issues (Doctoral dissertation). (Order No. 8509484). Available from ProQuest Dissertations \& Theses Global. (303286646).

Hosek, A. M., \& Thompson, J. (2009). Communication privacy management and college instruction: Exploring the rules and boundaries that frame instructor private disclosures. Communication Education, 58, 327-349. doi:10.1080/03634520902777585 
Huberty, C. J., \& Petoskey, M. D. (2000). Multivariate analysis of variance and covariance. In H. Tinsley and S. Brown (Eds.), Handbook of applied multivariate statistics and mathematical modeling. New York, NY: Academic Press.

Hsiung, T. H., \& Olejnik, S. (1994). Power of pairwise multiple comparisons in the unequal variance case. Communications in Statistics-Simulation and Computation, 23, 691-710. doi:10.1080/03610919408813194

Johnston, L. D., O’Malley, P. M., Bachman, J. G., Schulenberg, J. E. \& Miech, R. A. (2016). Monitoring the Future national survey results on drug use, 1975-2015: Volume 2, College students and adults ages 19-55. Ann Arbor, MI: Institute for Social Research, The University of Michigan. Available at http://monitoringthefuture.org/pubs.html\#monographs

Keppel, G. (1991). Design and analysis: A researcher's handbook. Upper Saddle River, NJ: Prentice-Hall.

Keyton, J. (2010). Communication research: Asking questions, finding answers (3rd ed.). New York, NY: McGraw-Hill.

Komarraju, M., Musulkin, S., Bhattacharya, G. (2010). Role of student-faculty interactions in developing college students. Journal of College Student Development, 51, 332-342. doi:10.1353/csd.0.0137

LaFrance, M. (1979). Nonverbal synchrony and rapport: Analysis by the cross-lag panel technique. Social Psychology Quarterly, 42(1), 66-70. doi:10.2307/3033875

LaFrance, M., \& Broadbent, M. (1976). Group rapport: Posture sharing as a nonverbal indicator. Group \& Organization Studies, 1, 328-333. doi:10.1177/105960117600100307 
Lance, C. E., Butts, M. M., \& Michels, L. C. (2006). The sources of four commonly reported cutoff criteria: What did they really say?. Organizational Research Methods, 9(2), 202220. doi:10.1177/1094428105284919

Lederman, L. C., \& Stewart, L. P. (2005). Changing the culture of college drinking: A socially situated health communication campaign. Cresskill, NJ: Hampton Press.

Lederman, L. C., Stewart, L. P., \& Russ, T. L. (2007). Addressing college drinking through curriculum infusion: A study of the use of experience-based learning in the communication classroom. Communication Education, 56, 476-494. doi10.1080/03634520701531464

Lincoln, Y. S., \& Guba, E. G. (1985). Naturalistic Inquiry. Newbury Park, CA: Sage.

Lix, L. M., Keselman, J. C., \& Keselman, H. J. (1996). Consequences of assumption violations revisited: A quantitative review of alternatives to the one-way analysis of variance $\mathrm{F}$ test. Review of Educational Research, 66, 579-619. doi:10.3102/00346543066004579

Lui, M., Spaeth, L., \& Fread, D. (2013). Exploring functions of binge drinking among first year college students. Journal of the Communication, Speech \& Theatre Association of North Dakota, 26, 40-49. Retrieved from https://drive.google.com/file/d/0B_ZNumnqzQN_Sm85NWFNVFFfbTA/view

Mack, N., Woodsong, C. M., MacQueen, K. M., Guest, G., \& Namey, E. (2005). Qualitative research methods: A data collector's field guide. Research Triangle Park, NC: Family Health International. 
Martin, M. M., Chesebro, J. L., \& Mottet, T. P. (1997). Students' perceptions of instructors' sociocommunicative style and the influence on instructor credibility and situational motivation. Communication Research Reports, 14, 431-440.

doi:10.1080/08824099709388686

Martinez-Egger, A. D., \& Powers, W. G. (2007). Student respect for a teacher: Measurement and relationships to teacher credibility and classroom behavior perceptions. Human Communication, 10(2), 145-155. Retrieved from http://citeseerx.ist.psu.edu/viewdoc/download?doi=10.1.1.614.6038\&rep=rep1\&type=pdf

Mazer, J. P., \& Graham, E. E. (2015). Measurement in instructional communication research: A decade in review. Communication Education, 64, 208-240. doi:10.1080/03634523.2014.1002509

McCroskey, J. C., Richmond, V. P., \& Daly, J. A. (1975). The development of a measure of perceived homophily in interpersonal communication. Human Communication Research, 1, 323-332. doi:10.1111/j.1468-2958.1975.tb00281.x

McCroskey, J. C., Richmond, V. P., \& McCroskey, L. L. (2006). An introduction to communication in the classroom: The role of communication in teaching and training. Boston, MA: Allyn \& Bacon.

McCroskey, J. C., \& Teven, J. J. (1999). Goodwill: A reexamination of the construct and its measurement. Communications Monographs, 66, 90-103. doi:10.1080/03637759909376464

McCroskey, J. C., Valencic, K. M., \& Richmond, V. P. (2004). Toward a general model of instructional communication. Communication Quarterly, 52, 197-210. doi:10.1080/01463370409370192 
McCroskey, L. L., McCroskey, J. C., \& Richmond, V. P. (2006). Analysis and improvement of the measurement of interpersonal attraction and homophily. Communication Quarterly, 54, 1-31. doi:10.1080/01463370500270322

McGovern, P. E., Zhang, J., Tang, J., Zhang, Z., Hall, G. R., Moreau, R. A., ... Wang, C. (2004). Fermented beverages of pre- and proto-historic China. Proceedings of the National Academy of Sciences, 101, 17593-17598. doi:10.1073/pnas.0407921102

Miller, A. N., Katt, J. A., Brown, T., \& Sivo, S. A. (2014). The relationship of instructor selfdisclosure, nonverbal immediacy, and credibility to student incivility in the college classroom. Communication Education, 63, 1-16. doi:10.1080/03634523.2013.835054

Morgan, D. L. (1996). Focus groups as qualitative research (Vol. 16). Thousand Oaks, CA: Sage.

Murphy, E., \& Rodríguez-Manzanares, M. A. (2012). Rapport in distance education. The International Review of Research in Open and Distributed Learning, 13(1), 167-190. Retrieved from http://www.irrodl.org/index.php/irrodl/article/download/1057/2125

Myers, S. A. (2004). The relationship between perceived instructor credibility in college student in-class and out-of-class communication. Communication Reports, 17, 129-137. doi:10.1080/08934210409389382

Myers, S. A., Brann, M., \& Members of Comm 600. (2009). College students' perceptions of how instructors establish and enhance credibility through self-disclosure. Qualitative Research Reports in Communication, 10, 9-16. doi:10.1080/17459430902751808

Meyers, L. S., Gamst, G., \& Guarino, A. J. (2017). Applied multivariate research: Design and interpretation ( $3^{\text {rd }}$ ed.). Thousand Oaks, CA: Sage Publishers. 
Myers, S. A., \& Huebner, A. D. (2011). The relationship between students' motives to communicate with their instructors and perceived instructor credibility, attractiveness, and homophily. College Student Journal, 45(1), 84-92. Retrieved from http://go.galegroup.com

North Dakota State University. (2014). 2014 NDSU Faculty and Staff Alcohol and Other Drugs Perceptions and Communication Survey. Retrieved from https://www.ndsu.edu/fileadmin/alcoholinfo/2014_NDSU_Fac_Staff_Survey_Summary. pdf

Nunziata, A. M. (2007, November). College student perceptions of instructor communication privacy management. Paper presented at the annual meeting of the National Communication Association, Chicago, IL.

Perkins, H. W. (1997). College student misperceptions of alcohol and other drug norms among peers: Exploring causes, consequences, and implications for prevention programs. In The Higher Education Center for Alcohol and Other Drug Prevention (Ed.), Designing alcohol and other drug prevention programs in higher education: Bringing theory into practice (pp. 177-206). Newton, MA: U.S. Department of Education.

Perkins, H. W. (2002a). Social norms and the prevention of alcohol misuse in collegiate contexts. Journal of Studies on Alcohol, 63(Suppl. 14), 164-172. doi:10.15288/jsas.2002.s14.164

Perkins, H. W. (2002b). Surveying the damage: A review of research on consequences of alcohol misuse in college populations. Journal of Studies on Alcohol, 63(Suppl. 14), 91-100. doi:10.15288/jsas.2002.s14.91 
Perkins, H. W., \& Craig, D. W. (2003). The Hobart and William Smith colleges experiment: A synergistic social norms approach using print, electronic media, and curriculum infusion to reduce collegiate problem drinking. In H. W. Perkins (Ed.), The social norms approach to preventing school and college age substance abuse: A handbook for educators, counselors, and clinicians (pp. 35-64). San Francisco, CA: Jossey-Bass.

Perkins, H. W., Haines, M. P., \& Rice, R. (2005). Misperceiving the college drinking norm and related problems: A nationwide study of exposure to prevention information, perceived norms and student alcohol misuse. Journal of studies on alcohol, 66, 470-478. doi:10.15288/jsa.2005.66.470

Perkins, H. W., Meilman, P. W., Leichliter, J. S., Cashin, J. R., \& Presley, C. A. (1999). Misperceptions of the norms for the frequency of alcohol and other drug use on college campuses. Journal of American College Health, 47, 253-258.

doi:10.1080/07448489909595656

Perkins, H. W., \& Wechsler, H. (1996). Variation in perceived college drinking norms and its impact on alcohol abuse: A nationwide study. Journal of Drug Issues, 26, 961-974. doi:10.1177/002204269602600413

Powell, L., Hamilton, T., Hickson, M., \& Stuckey, J. (2001). The relationship of homophily to verbal and nonverbal immediacy in the classroom. Communication Research Reports, 18, 217-222. doi:10.1080/08824090109384801

Random House dictionary of the English language (2nd ed.). (1987). New York, NY: Random House. 
Rocca, K. A. (2010). Student participation in the college classroom: An extended multidisciplinary literature review. Communication Education, 59, 185-213. doi:10.1080/03634520903505936

Rocca, K. A., \& McCroskey, J. C. (1999). The interrelationship of student ratings of instructors' immediacy, verbal aggressiveness, homophily, and interpersonal attraction. Communication education, 48, 308-316. doi:10.1080/03634529909379181

Ryan, R. G., Wilson, J. H., \& Pugh, J. L. (2011). Psychometric characteristics of the professorstudent rapport scale. Teaching of Psychology, 38, 135-141. doi:10.1177/0098628311411894

Samuolis, J., Lazowski, A., \& Kessler, J. (2016). Evaluating the impact of curriculum infusion on US college students' alcohol use and academic performance. Health Education Journal, 75, 736-743. doi:10.1177/0017896916629815

Schlesselman, L. S., Nobre, C., \& English, C. D. (2011). Alcohol attitudes and behaviors among faculty at US schools and colleges of pharmacy. Pharmacy Practice, 9, 236-241. doi:10.4321/s1886-36552011000400009

Schrodt, P. (2003). Students' appraisals of instructors as a function of students' perceptions of instructors' aggressive communication. Communication Education, 52, 106-121. doi:10.1080/03634520302468

Schrodt, P., Turman, P. D., \& Soliz, J. (2006). Perceived understanding as a mediator of perceived teacher confirmation and students' ratings of instruction. Communication Education, 55, 370-388. doi:10.1080/03634520600879196 
Stewart, L. P., Lederman, U. C., Golubow, M., Cattafesta, J. L., Goodhart, F. W., Powell, R. L., \& Laitman, L. (2002). Applying communication theories to prevent dangerous drinking among college students: The RU sure campaign. Communication Studies, 53(4), 381399. doi:10.1080/10510970209388599

Strauss, A., \& Corbin, J. (1998). Basics of qualitative research: Techniques and procedures for developing grounded theory ( $2^{\text {nd }}$ ed.). Thousand Oaks, CA: Sage.

Substance Abuse and Mental Health Services Administration. (2014). Results from the 2013 National Survey on Drug Use and Health: Summary of National Findings, NSDUH Series H-48, HHS Publication No. (SMA) 14-4863. Rockville, MD: Substance Abuse and Mental Health Services Administration. Retrieved from http://www.samhsa.gov/data/

Teven, J. J. (2001). The relationship among teacher characteristics and perceived caring. Communication Education, 50, 159-169. doi:10.1080/03634520109379241

Teven, J. J., \& Hanson, T. L. (2004). The impact of teacher immediacy and perceived caring on teacher competence and trustworthiness. Communication Quarterly, 52, 39-53. doi:10.1080/01463370409370177

Teven, J. J., \& McCroskey, J. C. (1997). The relationship of perceived teacher caring with student learning and teacher evaluation. Communication Education, 46, 1-9. doi:10.1080/03634529709379069

Tibbles, D., Richmond, V., McCroskey, J., \& Weber, K. (2008). Organizational orientations in an instructional setting. Communication Education, 57, 389-407. doi:10.1080/03634520801930095

Vangsness Frisch, J. M. (2016). Faculty and alcohol use communication (Order No. 10118526). Available from ProQuest Dissertations \& Theses Global. (1795076405). 
Wang, Z., Novak, H., Scofield-Snow, H., Traylor, S., \& Zhou, Y. (2015). Am I disclosing too much? Student perceptions of teacher credibility via Facebook. The Journal of Social Media in Society, 4(1), 5-37. Retrieved from http://www.thejsms.org/tsmri/index.php/TSMRI/article/view/22/49

Wanzer, M. B., Frymier, A. B., Wojtaszczyk, A. M., \& Smith, T. (2006). Appropriate and inappropriate uses of humor by teachers. Communication Education, 55, 178-196. doi:10.1080/03634520600566132

Welch, B. L. (1951). On the comparison of several mean values: An alternative approach. Biometrika, 38, 330-336. doi:10.1093/biomet/38.3-4.330

White, S., Park, Y. S., \& Cordero, E. D. (2010). Impact of curriculum infusion on college students' drinking behaviors. Journal of American College Health, 58, 515-522. doi:10.1080/07448481003621726

Wilson, J. H., Ryan, R. G., \& Pugh, J. L. (2010). Professor-student rapport scale predicts student outcomes. Teaching of Psychology, 37, 246-251. doi:10.1080/00986283.2010.510976 


\section{APPENDIX A: POSITIVE STUDENT OUTCOMES FROM INSTRUCTOR CREDIBILITY}

Table 9

Positive Student Outcomes from Perceived Instructor Credibility

Student Outcome

Author(s) and Year of Publication

\begin{tabular}{ll}
\hline Greater Motivation to Learn & $\begin{array}{l}\text { Frymier and Thomson (1992); Martin, } \\
\text { Chesebro, and Mottet (1997); Tibbles, } \\
\text { Richmond, McCroskey and Weber (2008) }\end{array}$ \\
& $\begin{array}{l}\text { Beatty and Zahn (1990); McCroskey, } \\
\text { Valencic, and Richmond (2004); Teven } \\
\text { (2001); Teven and McCroskey (1997); } \\
\text { Tibbles et al. (2008) }\end{array}$ \\
Increased Cognitive Learning & $\begin{array}{l}\text { J. C. McCroskey et al. (2004); Teven and } \\
\text { McCroskey (1997); Tibbles et al. (2008) }\end{array}$ \\
Increased Communication with Instructor & $\begin{array}{l}\text { Myers (2004) } \\
\text { Schrodt (2003); Schrodt, Turman, \& Soliz, } \\
\text { Feel Better Understood by Instructor }\end{array}$ \\
Perceive More Justice in The Classroom & Chory (2007) \\
Increased Respect for Instructor & Martinez-Egger and Powers (2007)
\end{tabular}

Note. Table 9 summarizes the findings of Finn et al.'s (2009) meta-analysis of communication research regarding positive student outcomes associated with perceived instructor credibility. 


\section{APPENDIX B: CHARTS}

\section{Descriptive Drinking Norms}

"Students here at [name of university] drink more than students at other colleges and universities."

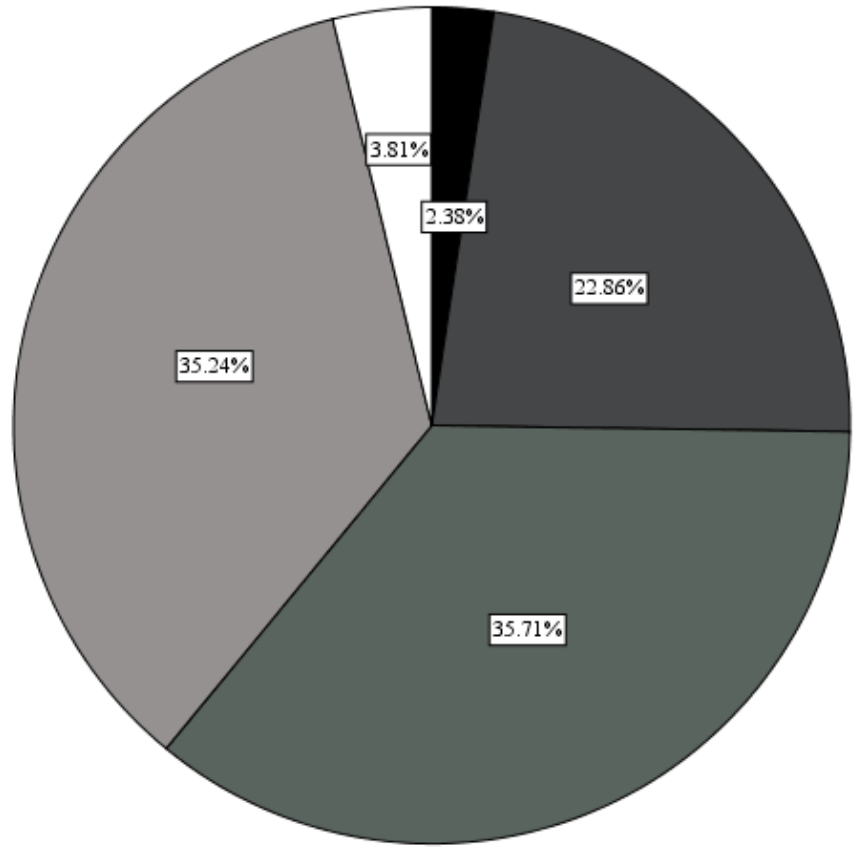

Strongly Agree

$\square$ Agree

Neither Agree nor Disagree

$\square$ Disagree

Strongly Disagree

Figure 2. Descriptive Drinking Norms Circle Graph.

Injunctive Drinking Norms

"Most [name of university] students think it's okay to get drunk at parties."

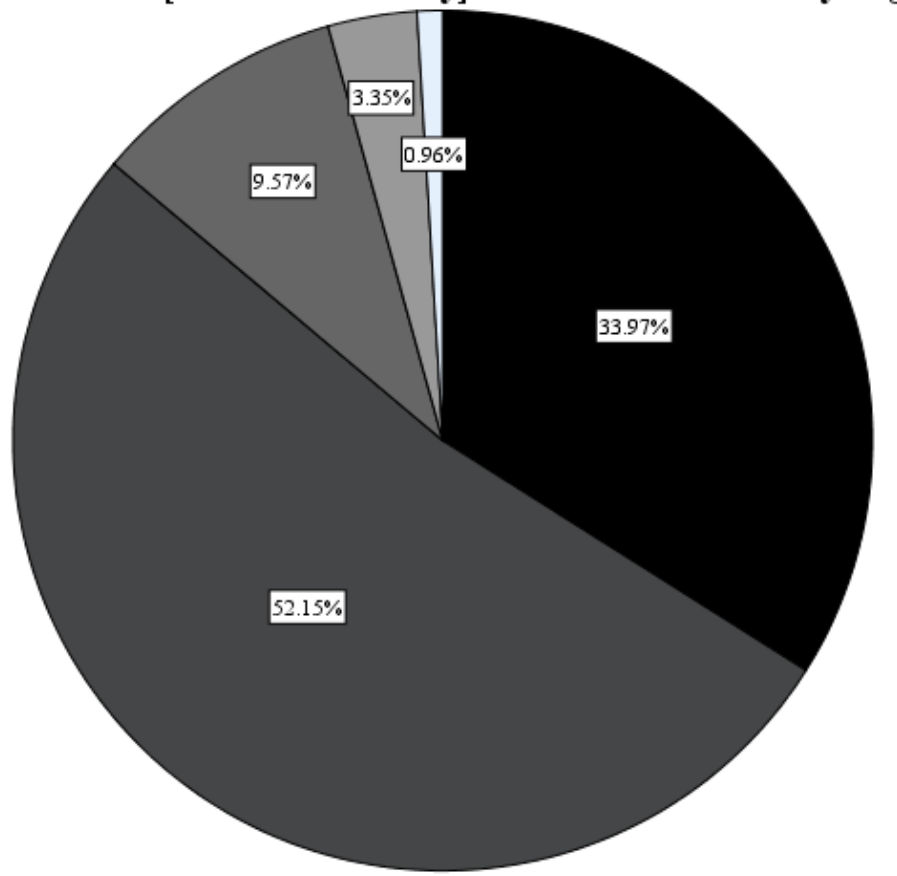

Strongly Agree

Agree

Neither Agree nor Disagree

$\square$ Disagree

$\square$ Strongly Disagree

Figure 3. Injunctive Drinking Norms Question One Circle Graph. 


\section{Injunctive Drinking Norms}

"Drinking is considered to be a desirable activity on this campus."

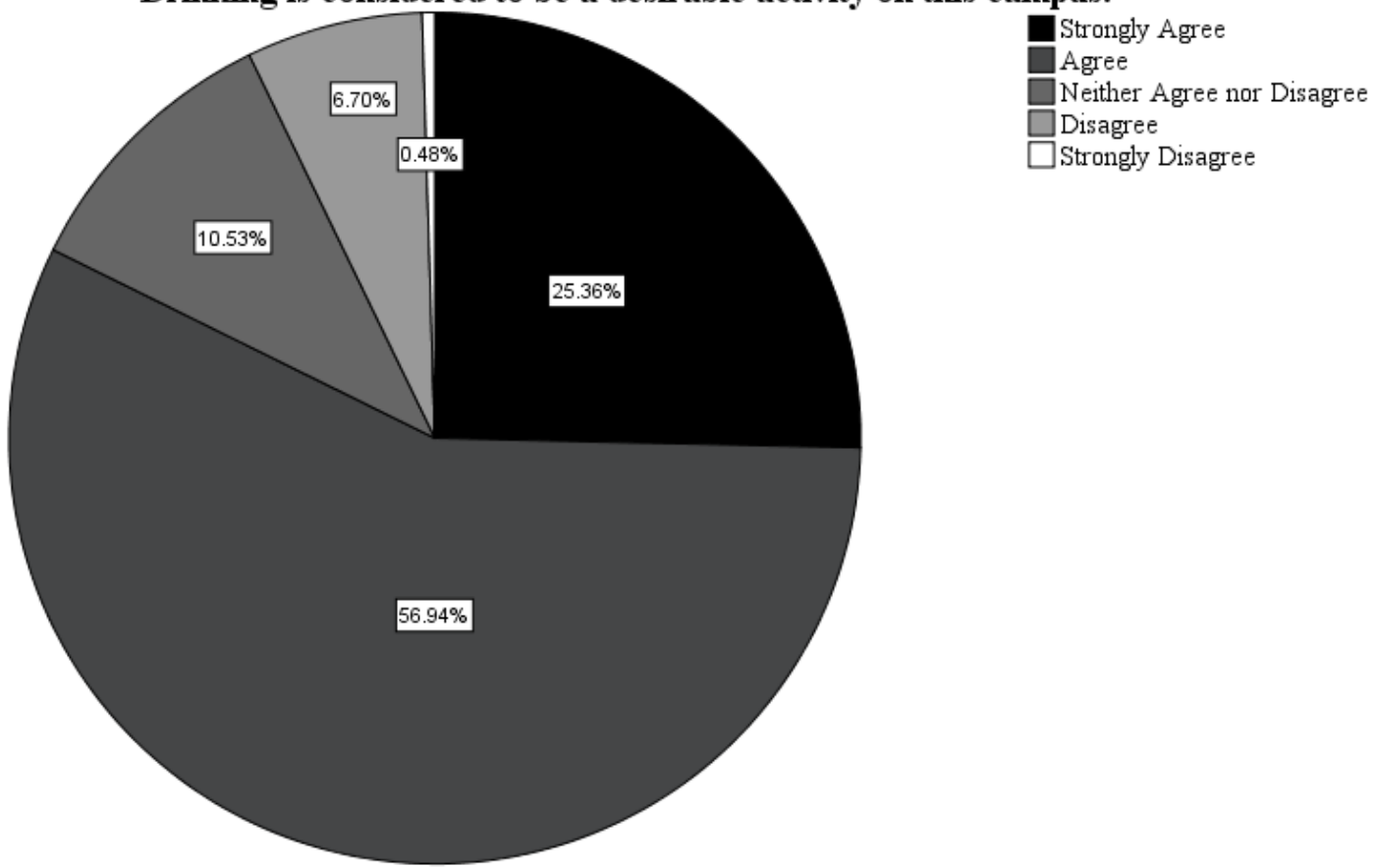

Figure 4. Injunctive Drinking Norms Questions Two Circle Graph. 


\section{APPENDIX C: SURVEY}

\section{Before Viewing Vignette}

Descriptive drinking norms scale (Crawford \& Novak, 2010)

1) How many alcoholic drinks (beer, wine, shot of spirits, etc.) does a typical student at Illinois State University who shares your gender identity consume per sitting?

2) How many alcoholic drinks (beer, wine, shot of spirits, etc.) does a typical student at Illinois State University who shares your gender identity consume per week?

3) How many times is a typical student at Illinois State University who shares your gender identity intoxicated during an average month?

4) Students here at Illinois State University drink more than students at other colleges and universities.

1. Strongly Disagree

2. Disagree

3. Agree

4. Strongly Agree

Injunctive drinking norms scale (Crawford \& Novak, 2010, p. 73)

5) Most ISU students think it's okay to get drunk at parties.

1. Strongly disagree

2. Disagree

3. Agree

4. Strongly agree

6) Drinking is considered to be a desirable activity on this campus.

1. Strongly disagree

2. Disagree

3. Agree

4. Strongly agree

While Viewing Vignette

Rapport (Frisby \& Martin, 2010)

7) In thinking about my hypothetical relationship with this instructor, I would enjoy interacting with them.

1. Strongly disagree

2. Disagree

3. Neutral

4. Agree

5. Strongly agree

8) This instructor might create a feeling of "warmth" in our relationship.

1. Strongly disagree

2. Disagree

3. Neutral

4. Agree

5. Strongly agree

9) This instructor relates well to me.

1. Strongly disagree

2. Disagree

3. Neutral 


\section{Agree}

5. Strongly agree

10) In thinking about this relationship, I have a harmonious relationship with this instructor.

1. Strongly disagree

2. Disagree

3. Neutral

4. Agree

5. Strongly agree

11) This instructor has a good sense of humor.

1. Strongly disagree

2. Disagree

3. Neutral

4. Agree

5. Strongly agree

12) I would be comfortable interacting with this instructor.

1. Strongly disagree

2. Disagree

3. Neutral

4. Agree

5. Strongly agree

13) I feel like there could be a "bond"' between the hypothetical instructor and myself.

1. Strongly disagree

2. Disagree

3. Neutral

4. Agree

5. Strongly agree

14) I would look forward to seeing this instructor in class.

1. Strongly disagree

2. Disagree

3. Neutral

4. Agree

5. Strongly agree

15) I would strongly care about this instructor.

1. Strongly disagree

2. Disagree

3. Neutral

4. Agree

5. Strongly agree

16) I could have a close relationship with this instructor.

1. Strongly disagree

2. Disagree

3. Neutral

4. Agree

5. Strongly agree 
Regarding the hypothetical instructor in this example:

17) This person thinks like me.

1. Strongly disagree

2. Disagree

3. Neutral

4. Agree

5. Strongly agree

18) This person doesn't behave like me. *

1. Strongly disagree

2. Disagree

3. Neutral

4. Agree

5. Strongly agree

19) This person shares my values. *

1. Strongly disagree

2. Disagree

3. Neutral

4. Agree

5. Strongly agree

20) This person is like me.

1. Strongly disagree

2. Disagree

3. Neutral

4. Agree

5. Strongly agree

21) This person treats people like I do.

1. Strongly disagree

2. Disagree

3. Neutral

4. Agree

5. Strongly agree

22) This person doesn't think like me. *

1. Strongly disagree

2. Disagree

3. Neutral

4. Agree

5. Strongly agree

23) This person is similar to me.

1. Strongly disagree

2. Disagree

3. Neutral

4. Agree

5. Strongly agree 
24) This person doesn't share my values. *

1. Strongly disagree

2. Disagree

3. Neutral

4. Agree

5. Strongly agree

25) This person behaves like me.

1. Strongly disagree

2. Disagree

3. Neutral

4. Agree

5. Strongly agree

26) This person doesn't treat people like I do. *

1. Strongly disagree

2. Disagree

3. Neutral

4. Agree

5. Strongly agree

27) This person has thoughts and ideas that are similar to mine.

1. Strongly disagree

2. Disagree

3. Neutral

4. Agree

5. Strongly agree

28) This person expresses attitudes different from mine. *

1. Strongly disagree

2. Disagree

3. Neutral

4. Agree

5. Strongly agree

29) This person has a lot in common with me.

1. Strongly disagree

2. Disagree

3. Neutral

4. Agree

5. Strongly agree

$*=$ Reverse coded prior to analysis

Teacher Credibility (McCroskey, J. C., \& Teven, J. J., 1999)

30) Intelligent 1234567 Unintelligent*

31) Untrained 1234567 Trained

32) Cares about me 1234567 Doesn't care about me*

33) Honest 1234567 Dishonest*

34) Has my interests at heart 1234567 Doesn't have my interests at heart* 35) Untrustworthy 1234567 Trustworthy 
36) Inexpert 1234567 Expert

37) Self-centered 1234567 Not self-centered

38) Concerned with me 1234567 Not concerned with me*

39) Honorable 1234567 Dishonorable*

40) Informed 1234567 Uninformed*

41) Moral 1234567 Immoral*

42) Incompetent 1234567 Competent

43) Unethical 1234567 Ethical

44) Insensitive 1234567 Sensitive

45) Bright 1234567 Stupid*

46) Phony 1234567 Genuine

47) Not understanding 1234567 Understanding

* = Reverse coded prior to analysis

\section{Manipulation Check}

1) Please indicate how well each of the following options describes the context of the instructor's statements above. The closer your selection is to does not describe at all or describes very well, the more certain you are of your evaluation.

1. Instructor advocating for safe drinking behavior

Does not

Describe at All

O
○
Describes Very

Well

O

2. Mentioning alcohol as part of the curriculum

Does not

Describe at All

Describes Very

Well

O

O

○

○

3. Instructor discussing their personal alcohol use behavior Does not Describe at All

O

O

4. Student past alcohol use

Does not

Describe at All

$\circ$

5. Student future alcohol use

Does not

Describe at All

Describes Very
Well
$\circ$

Describes Very

Well

o

Describes Very

Well 
After Viewing Vignette

1) What is your gender identity?

$$
\text { Demographics }
$$

1. Agender

2. Female

3. Fluid/genderqueer

4. Male

5. Questioning/unsure

6. Other

2) Please select which of the following racial identities you identify with.

1. African American

2. Asian/Pacific Islander

3. Hispanic/Latino(a)

4. Middle Eastern

5. Native American

6. White

7. Other:

3) What is the highest level of education you have completed?

1. High School

2. GED

3. Associate's Degree

4. Bachelor's Degree

5. Master's Degree

6. Doctorate Degree

7. Other: 


\section{APPENDIX D: VIGNETTES}

\section{Student Past Alcohol Use}

\section{Please read this section carefully, you will need to keep this information in mind as you answer the next several sets of questions.}

Imagine you are in a class with a university instructor who casually made the following statements in the classroom over the course of a semester...

"What's wrong? Why are you all so tired? Is it because the bar had half-priced pitchers last night?"

"In the past, a student decided to get belligerently drunk on the field trip; I assume that won't be a problem this year..."

"I'm sure you are all incredibly hungover with the Cubs just winning the world series and all, but please do your best to pay attention."

"I can't give you an excused absence from class just because you emailed me saying that you're feeling sick. I need a note from Student Health Services or your doctor because too many students are just hungover from drinking and not actually sick."

"You know, this 8:00 am class wouldn't be as difficult to attend if you didn't go out drinking the night before."

\section{Student Future Alcohol Use}

Imagine you are in a class with a university instructor who casually made the following statements in the classroom over the course of a semester...

"If you go online, you can find a fun drinking game to play while you watch the presidential debates tonight!"

"I've decided to push the midterm until after homecoming. I assume many of you will be drinking over the weekend and I want everyone to perform to the best of their ability on this exam."

"I know you are all going to go out and party tonight, but make sure to look over your notes for Monday's test."

"No matter how much you want to go take advantage of half-priced pitchers at the bar this week, I fully expect all of you to be in class Wednesday evening."

"We're going to just do an in-class assignment today, but that doesn't mean you can rush through this so you can be drunk by 4:00 pm." 


\section{Advocating for Safe Student Alcohol Use}

Imagine you are in a class with a university instructor who casually made the following statements in the classroom over the course of a semester...

"Look, I understand some of you may go out drinking homecoming weekend, but please do your best to be safe - and especially be careful not to leave your drink unattended."

"If you plan on going to the bars or a party this Halloween, try to stay safe and use the buddy system. Also, if you're going somewhere that isn't within walking distance, be sure to use an Uber or have a designated driver for the night."

"One of the leading causes of fatal car accidents is drunk driving. Keep that in mind when you go out this weekend."

"I want you all to learn from a tragedy that happened to my family. My son was an alcoholic in college and he passed away in a drunk driving accident."

"A few semesters ago, there was a student who was dropped off at her apartment but was too intoxicated to get inside and ended up passing away from exposure to the cold. So, please, be safe, bundle up and behave responsibly if you go out drinking."

\section{Alcohol as Part of the Curriculum}

Imagine you are in a class with a university instructor who casually made the following statements in the classroom over the course of a semester...

[In an economics classroom] "When you have a low income, you tend to buy inferior goods, for example, Natty Light. However, as your income increases, you have the option to purchase more normal goods, such as Bud Lite."

[In an introductory math class] "By a show of hands, who goes out and drinks on the weekends? [After counting the number of hands raised] Great! Now, using what we learned about proportions, let's estimate what percentage of the student body drinks alcohol on the weekend based on the proportion of students in this room who do."

"Say, for example, that the last time you consumed alcohol you did something really embarrassing and the next day you swore you'd never drink again. Two weeks later, though, your best friend turns 21 and wants you to go to the bar with them. The internal struggle between wanting to avoid drinking because it causes you to embarrass yourself and wanting to have fun and party with your friend is an example of cognitive dissonance theory in action." 


\section{Instructor Personal Alcohol Use Behaviors}

Imagine you are in a class with a university instructor who casually made the following statements in the classroom over the course of a semester...

"I remember when I was a student, my favorite place to do homework was a bar down the street from my apartment."

"This coffee is good, but a little bit of Baileys would really help this day get a little better."

[After fumbling over their words] "Ah, sorry about that. It must be the Nyquil—or the bourbon I chased it with."

"I'm a big fan of craft beers. My personal favorite is a local Chicago pale ale called Daisy Cutter from Half Acre brewery."

[While pouring a Diet Coke into an empty glass] "Wow, I sure wish this was a cold beer instead of a soft drink..." 